\title{
Genome Sequence of an M3 Strain of Streptococcus pyogenes Reveals a Large-Scale Genomic Rearrangement in Invasive Strains and New Insights into Phage Evolution
}

\author{
Ichiro Nakagawa, ${ }^{1,7}$ Ken Kurokawa, ${ }^{2}$ Atsushi Yamashita, ${ }^{3}$ Masanobu Nakata, ${ }^{1}$ \\ Yusuke Tomiyasu, ${ }^{1}$ Nobuo Okahashi, ${ }^{1}$ Shigetada Kawabata, ${ }^{1,4}$ Kiyoshi Yamazaki, ${ }^{2}$ \\ Tadayoshi Shiba, ${ }^{5}$ Teruo Yasunaga, ${ }^{2}$ Hideo Hayashi, ${ }^{6}$ Masahira Hattori, ${ }^{3}$ \\ and Shigeyuki Hamada ${ }^{1}$ \\ ${ }^{1}$ Department of Oral and Molecular Microbiology, Osaka University Graduate School of Dentistry, Suita-Osaka 565-0871, \\ Japan; ${ }^{2}$ Genome Information Research Center, Osaka University, Suita-Osaka 565-0871, Japan; ${ }^{3}$ Kitasato Institute for Life \\ Sciences, Kitasato University, Sagamihara-Kanagawa 228-8555, Japan; ${ }^{4}$ PRESTO, Japan Science and Technology \\ Corporation, Kawaguchi, Saitama 332-0012, Japan; ${ }^{5}$ School of Science, Kitasato University, Sagamihara-Kanagawa \\ 228-8555, Japan; ' Institute of Basic Medical Sciences, University of Tsukuba, Tsukuba-Ibaraki 305-8575, Japan
}

\begin{abstract}
Group A streptococcus (GAS) is a gram-positive bacterial pathogen that causes various suppurative infections and nonsuppurative sequelae. Since the late 1980s, streptococcal toxic-shock like syndrome (STSS) and severe invasive GAS infections have been reported globally. Here we sequenced the genome of serotype M3 strain SSI-1, isolated from an STSS patient in Japan, and compared it with those of other GAS strains. The SSI-1 genome is composed of 1,884,275 bp, and $1.7 \mathrm{Mb}$ of the sequence is highly conserved relative to strain SF370 (serotype M1) and MGAS8232 (serotype M18), and almost completely conserved relative to strain MGAS315 (serotype M3). However, a large genomic rearrangement has been shown to occur across the replication axis between the homologous rrn-comXI regions and between two prophage-coding regions across the replication axis. A total of 1 $\mathrm{Mb}$ of chromosomal DNA is inverted across the replication axis. Interestingly, the recombinations between the prophage regions are within the phage genes, and the genes encoding superantigens and mitogenic factors are interchanged between two prophages. This genomic rearrangement occurs in $65 \%$ of clinical isolates (64/94) collected after 1990, whereas it is found in only $25 \%$ of clinical isolates $(7 / 28)$ collected before 1985 . These observations indicate that streptococcal phages represent important plasticity regions in the GAS chromosome where recombination between homologous phage genes can occur and result not only in new phage derivatives, but also in large chromosomal rearrangements.
\end{abstract}

[Supplemental material is available online at www.genome.org. The sequence data from this study have been submitted to DDB] under accession no. BA000034. The following individuals kindly provided reagents, samples, or unpublished information as indicated in the paper: K. Kikuchi, S. Murai, M. Ohta, T. Ikebe, and H. Watanabe.]

Group A Streptococcus pyogenes (GAS) is responsible for a variety of suppurative infections, including pharyngitis, scarlet fever, impetigo, and cellulitis and for nonsuppurative sequelae, such as acute rheumatic fever, acute glomerulonephritis, and reactive arthritis (Cunningham 2000). Although GAS is still sensitive to classical antibiotics such as penicillin, an unexplained resurgence of GAS infections has been reported since the mid-1980s. Outbreaks of rheumatic fever have also been reported in several states of the USA and other countries (Cone et al. 1987; Kaplan 1991). Furthermore, in the late

\section{${ }^{7}$ Corresponding author.}

E-MAIL ichiro@dent.osaka-u.ac.jp; FAX +81-6-6878-4755.

Article and publication are at http://www.genome.org/cgi/doi/10.1101/ gr.1096703. 1980s, streptococcal toxic shock-like syndrome (STSS), bacteremia, and severe invasive group A streptococcal skin and soft tissue infections were reported in the USA, Europe, and Japan (Musher et al. 1996; Holm et al. 1997; Murase et al. 1999). These severe and invasive diseases exhibit high morbidity and mortality. In severe cases, GAS invades the skin and soft tissues and destroys the infected tissues or limbs, and is therefore called the "flesh-eating" bacterium (Stevens 1999). Epidemiological data indicate a clonal expansion of serotype strains (i.e., serotypes M1 and M3) in severe invasive infections of GAS (Musser et al. 1991). These results suggest that unknown virulence factors that cause STSS have been acquired either by horizontal transfer or by genetic changes occurring in these strains (Inagaki et al. 2000). The genome of a serotype M1 organism isolated from a wound infection (Fer- 
retti et al. 2001), a serotype M18 organism from a patient with acute rheumatic fever (Smoot et al. 2002), and a serotype M3 organism from an STSS patient (Beres et al. 2002) were recently sequenced. Comparative analysis of these three strains provided interesting genomic information about GAS pathogenicity. However, there is only limited genomic information available about GAS strains associated with severe, invasive infections. Comparative genomic analyses have been performed for other pathogenic bacteria such as Helicobacter pylori (Alm et al. 1999), Mycobacterium species (Cole 1998), and Chlamydia species (Read et al. 2000). These comparative studies indicate that the genes within closely related species are highly conserved, with the exception of inversions, translocations, phage integrations, and the mobile genetic elements. In particular, the genomic arrangement regions in $H$. pylori by inversion and translocation form a specific genetic segment called the "plasticity zone", and almost half of the strainspecific genes are included in this region (Alm et al. 1999). These observations suggest that the genes in plasticity zones have undergone genetic reorganization to a much higher degree than the rest of the chromosome, and this is thought to be related to the diversity of phenotypes seen in these organisms (Maeder et al. 1999; Hughes 2000). However, it is difficult to analyze genomic rearrangements using conventional methods such as pulsed-field gel electrophoresis (PFGE). Only comparative genomic analyses based on whole-genome sequences can provide useful information about genomic organization.

To develop effective prevention strategies or new therapeutic methods for these severe infections, it is necessary to understand the biology of this organism at the genomic level. As a first step in resolving the pathogenesis of severe infections, we sequenced the whole genome of a serotype M3 strain isolated from a patient with STSS in Japan, and compared the genomic sequence, genome structure, and gene variation with the genomes of M1, and M18 serotype organisms. In addition, we further compared two M3 organisms isolated in Japan and the United States. These genome sequences provide useful information about the evolutionary events associated with severe invasive GAS strains and the pandemic of recent GAS infections in advanced countries.

\section{RESULTS AND DISCUSSION}

\section{General Features of the Strain SSI-1 Genome}

The genome of strain SSI-1 is a single, circular chromosome of $1,894,275 \mathrm{bp}$ (Fig. 1). The size of the total genome is virtually identical to that of strains MGAS8232 and MGAS315, and is almost $38 \mathrm{~kb}$ larger than that of strain SF370 (Table 1). Strain SSI-1 contains 1861 open reading frames (ORFs) that cover $85.94 \%$ of the whole sequence, with an average size of $853 \mathrm{bp}$. Six regions in the SSI-1 genome are composed of prophage elements, and 341 ORFs are included in these regions. The sequence has been deposited in the DNA Data Bank of Japan (DDBJ; accession no. BA000034) and is available from our Web site (http://genome.gen-info.osaka-u.ac.jp/bacteria/ spyo/).

\section{Extensive Genomic Rearrangements in Strain SSI-1}

Alignment of the whole GAS genome (Fig. 2) shows the extent of genomic rearrangement in strain SSI-1 relative to the genomes of strains SF370, MGAS315, and MGAS8232. This is the most prominent difference and characteristic of the SSI-1 genome. The origins of DNA replication (ori; Suvorov and
Ferretti 2000) and dif-like termination sequence (Ferretti et al. 2001) are completely conserved among the four strains. Alignment analyses reveal clear X-shaped chromosomal rearrangements that are symmetrical across the ori/ter axis (replication axis; Fig. 2). We also determined the relative location of the homologous genes on the chromosomes of strains SSI- 1 and other S. pyogenes strains (Fig. 3A). The locations of genes around the ori region (from $1650 \mathrm{~kb}$ to $230 \mathrm{~kb}$ ) and around the ter region (from $920 \mathrm{~kb}$ to $1100 \mathrm{~kb}$ ) were almost completely conserved between strain SSI-1 and the other strains. However, the other homologous genes were translocated to an inverted position on the chromosome, indicating that these two segments are translocated to other replichores (Fig. 2). On the other hand, the locations of genes between strains SF370 and MGAS8232, and between strains SF370 and MGAS315 are conserved except for the phage genes (Fig. 3B). Therefore, these chromosomal segments are syntenic, except for small gaps encoding the genes of prophage or phage-like elements. As a consequence, the inversion in strain SSI-1 relative to other GAS strains does not change gene orientation relative to the replication axis, and produces the characteristic $\mathrm{X}$-shaped plot diagram (Fig. 3A; Eisen et al. 2000; Tillier and Collins 2000a). This characteristic X-shaped chromosomal inversion has also been found between Pyrococcus horikoshii and P. abyssi (Zivanovic et al. 1997; Makino and Suzuki 2001), and between Chlamydia pneumoniae and C. trachomatis (Read et al. 2000). However, comparison of the three GAS strains provides straightforward evidence of an intraspecies genomic rearrangement.

We further compared the order of orthologous genes between S. pyogenes and S. pneumoniae strains TIGR4 and R6, or S. agalactiae strain 2603V/R (Hoskins et al. 2001; Tettelin et al. 2001, 2002). As shown in Figure 3C, the X-shaped plot diagram is observed in comparison of GAS strain SSI-1 with $S$. pneumoniae TIGR4. Interestingly, an X-shaped plot diagram is also found in the comparison between the genomes of GAS strain SF370 and S. pneumoniae TIGR4. These observations indicate that the chromosomal inversion across the replication axis has frequently occurred in individual streptococcal species after branching from a common ancestor of the genus Streptococcus (Bentley et al. 1991). The gene order between strain SSI-1 and S. agalactiae is more highly conserved than between strain SF370 and S. agalactiae (Fig. 3D). The similarity of genome architecture of strain SSI-1 with S. agalactiae suggests two possibilities regarding the chromosomal inversion in the pyrogenic group of Streptococcus. One is that strain SSI1 , in which the ancestral chromosomal architecture is present, is the common ancestor of the pyrogenic group. The other is that this inversion has coincidentally occurred in both SSI-1 and S. agalactiae. However, the fact that the isolation frequency of clinical isolates with chromosomal inversion increased after 1985 (Suppl. Fig. A) clearly indicates that the chromosomal inversion found in SSI-1 and other recent isolates occurred very recently.

\section{Genomic Analysis of the Rearrangement in the rrn-comX Regions}

At the recombination sites near the ori region in strain SSI-1, we found a 5.6-kb-long homologous sequence, which included genes for 16S rRNA, tRNA-Ala, 23S rRNA, tRNA-Asn, tRNA-Arg, and the $\operatorname{com} X 1$ homolog in both regions. Our sequencing data show that the rearrangement breakpoint is located $41 \mathrm{bp}$ downstream from the $\operatorname{comX} 1$ homolog genes 


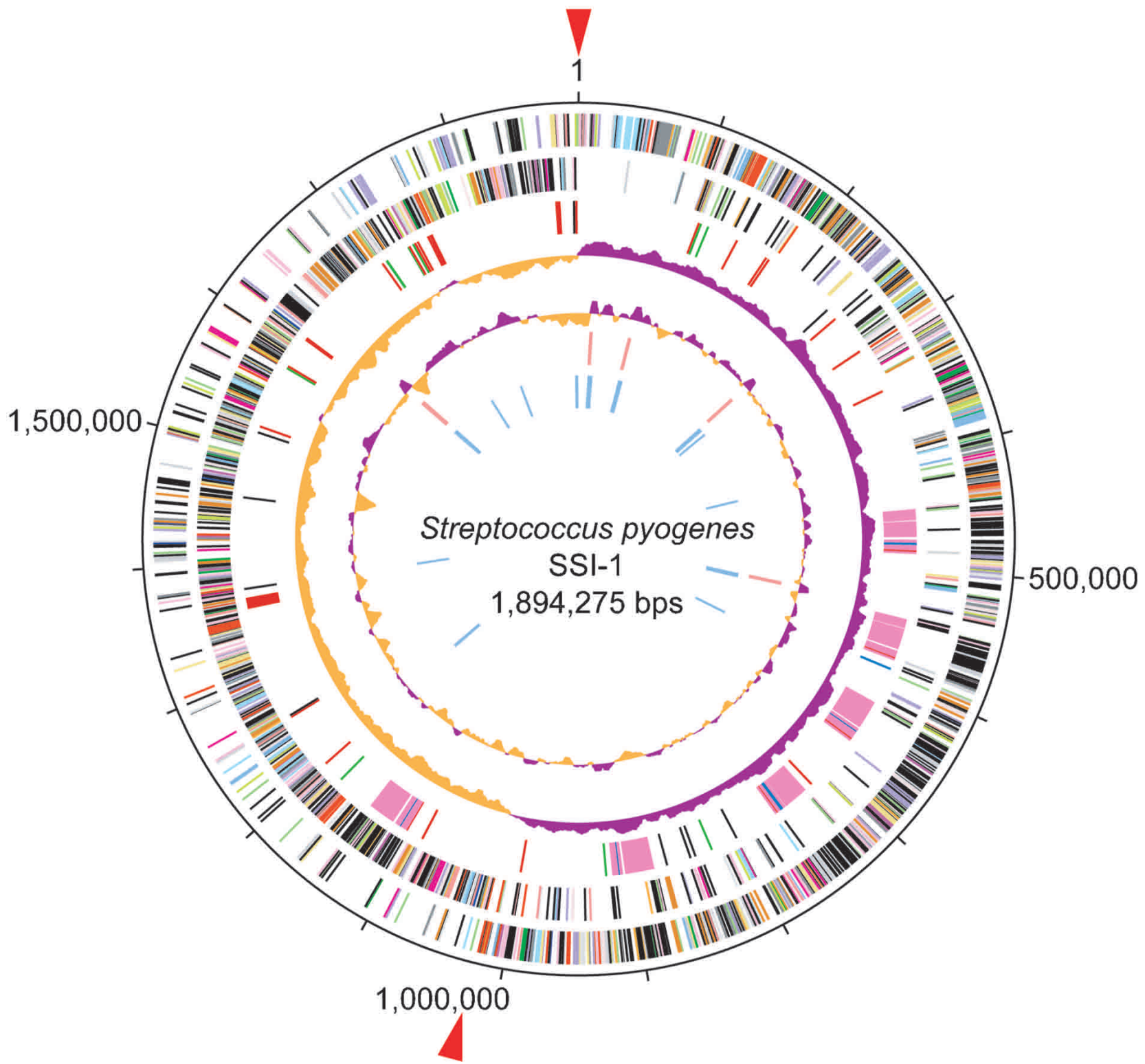

Figure 1 Circular map of GAS strain SSI-1. The outer circle shows the scale (bp). Rings 1 and 2 show the coding sequence by strands (ring 1 , clockwise; ring 2, counterclockwise). The predicted ORFs are distinguished by different colors in the COG classification. Ring 3: The genes for bacteriophage (pink), transposase genes and insertion sequence (black), adhesion molecules (green), hyaluronidase genes (blue), and other putative virulence factors (red). Ring 4: The GC skew analysis. Ring 5: The G+C contents. Rings 6 and 7: The ribosomal RNA (red) genes and transfer RNA (blue) genes identified in the genome. Red arrows: The origin of DNA replication (ori; Suvorov and Ferretti 2000) and the putative region of replication terminus (ter).

(SPs0226 and SPs1640), and this rearrangement breakpoint is completely conserved within other strains (Fig. 4A). To confirm the break-point in this region, we designed long-PCR primers (1718F and 952R). An 18-kb PCR product was clearly amplified from strain SSI-1, but not from SF370 (Fig. 4B). These observations indicate that the chromosomal recombination in this site may be due to a recA-dependent recombination between two 5.6-kb inverted repeats containing ribosomal operon and comX1 (Radding 1988; Tillier and Collins 2000b). In Salmonella typhimurium, inversion between large inverted repeats (over $5 \mathrm{~kb}$ ) separated by large intervals $(>60$ $\mathrm{kb}$ ) was shown to be recA- and recB-dependent (Segall and
Roth 1994). In addition, the chromosomal inversion between the ribosomal operons was reported between $S$. typhimurium and S. paratyphi A (Liu and Sanderson 1995). Therefore, our sequencing analysis represents clear evidence that longrepeated sequences across the replication axis can also induce large-scale chromosomal rearrangements within the same species of gram-positive bacteria.

Although the role of homologous recombination in genomic rearrangements across the replication axis has not been elucidated, Tillier and Collins (2000b) proposed an alternative model for the observed pattern of rearrangement. Gene translocation across the replication axis may result dur-

\section{Genome Research}


Table 1. General Features of S. pyogenes Strains SSI-1, SF370, MGAS315, and MGAS8232

\begin{tabular}{|c|c|c|c|c|}
\hline \multirow[b]{2}{*}{ Features } & \multicolumn{4}{|c|}{ Strains } \\
\hline & SSI-1 (M3) & $\mathrm{SF} 370^{\mathrm{a}}(\mathrm{M} 1)$ & MGAS315 ${ }^{\mathrm{b}}(\mathrm{M} 3)$ & MGAS8232 ${ }^{c}$ (M18) \\
\hline Length of sequence (bp) & $1,894,275$ & $1,852,441$ & $1,900,521$ & $1,895,017$ \\
\hline $\mathrm{G}+\mathrm{C}$ content & $37.93 \%$ & $38.51 \%$ & $38.6 \%$ & $38.5 \%$ \\
\hline \multicolumn{5}{|l|}{ Open reading frames } \\
\hline Percentage coding & $85.94 \%$ & $83.77 \%$ & $85.76 \%$ & $84.94 \%$ \\
\hline Protein coding region & 1861 & 1696 & 1865 & 1845 \\
\hline Average gene length (bp) & 853 & 915 & 874 & 872 \\
\hline \multicolumn{5}{|l|}{ SNPs (per gene) $)^{\mathrm{d}}$} \\
\hline Average number of SNPs & - & 11.53 & 0.05 & 12.61 \\
\hline Silent SNPs (sSNPs) & - & 6.40 & 0.02 & 7.26 \\
\hline Coding SNPs (cSNPs) & - & 5.13 & 0.03 & 5.35 \\
\hline \multicolumn{5}{|l|}{ RNA } \\
\hline Ribosomal RNA & 5 & 6 & 6 & 6 \\
\hline Transfer RNA & 57 & 60 & 60 & 60 \\
\hline tmRNA & 1 & 1 & 1 & 2 \\
\hline Transposon or IS & 21 & 17 & 22 & 25 \\
\hline \multicolumn{5}{|l|}{ Phage-related } \\
\hline Pro-phage & 6 & 4 & 6 & 5 \\
\hline Remnant & 4 & 4 & 3 & 3 \\
\hline
\end{tabular}

ing the process of genome replication because homologous recombination equidistant from the ori region will occur in close physical proximity between two replication forks, and single- or double-stranded DNA breaks have been implicated in illegitimate recombination (Kuzminov and Stahl 1999). In fact, two rrn-com $X$ regions are found equidistant from the ori region in the GAS genomes; thus, this model is in a good agreement with the genomic rearrangement mechanism of the GAS chromosome. In addition, sequence specificity may also affect the recombination of this site. It has been reported that a 240-bp chromosomal palindromic inverted repeat sequence is required for the repair of recombination from DNA cleavage of SbcCD nuclease (Leach et al. 1997). In the GAS genome, palindromic sequences (AAAAAAACAACAGGACAC TAATGTCCTGTTGTTTTTTT) are found just upstream of comX homologs (SPs0226 and SPs1640). This sequence specificity may also affect the site-specific recombination during homologous recombination.

\section{Unbalanced Genome Architecture by Phage Integration Affects the Chromosomal Inversion}

As shown in Figure 1, the locations of ori and ter are not exactly opposite each other, leading to an "unbalanced" genome in strain SSI-1. This unbalanced genome was also found in strains SF370 (Ferretti et al. 2001) and MGAS315 (Beres et al. 2002). Only MGAS8232 (Smoot et al. 2002) had a balanced genome architecture. Strain SSI-1 has six prophages in the genome; however, five prophage regions are found in the one replichore. These lopsided phage integrations into chromosomal DNA may result in an unsymmetrical genome architecture across the replication axis. This unbalancing of the genome might induce the chromosomal rearrangement for stabilizing the genome architecture. This type of genomic rearrangement (the adopt-adapt model) was also found in Salmonella enterica serovar Pollorum (Liu et al. 2002). The genomic balance was disrupted by the $157-\mathrm{kb}$ insertion near the ter region in S. enterica serovar Pollorum, and the genomic inversions are considered to occur between two homologous $r r n$ operons ( $r r n \mathrm{D} / \mathrm{E}$ and $r r n \mathrm{H} / \mathrm{G})$ and between two homologous insertions for rebalancing of the genome. In GAS genomes, we speculate that the "unbalanced" genomes found in strains SSI-1, SF370, and MGAS315 might be in flux by the phage integration. In fact, if the two phages found in strain SSI-1 (SPsP1 and SPsP2, totally about $80 \mathrm{~kb}$ ) are excised, the genome will be in balance, because each replichore is almost equal in length. These observations suggest that the phage integrations affect the balance of the choromosomal architecture. Therefore, the imbalance and rebalancing by the phage integrations may cause the chromosomal inversion in GAS.

\section{Chromosomal Inversion Triggers Streptococcal Phage Rearrangement}

The genomic rearrangement sites of strain SSI-1 around the ter region are coincident with the phage integration sites. Two SSI-1 phages, SPsP5 and SPsP6, are integrated at positions equidistant from the ter region (Fig. 4C). In comparison with strain SF370, the rearrangement break-points were 43 bp upstream from the integrase (int) gene of SPsP5 (SPs0877) and the tmRNA region, which is predicted to be a streptococcal T12 phage integration site in the SF370 genome (McShan et al. 1997). On the other hand, the rearrangement sites of strain SSI-1 are also found within the phage regions of MGAS315 and MGAS8232. The rearrangements occur between the holin genes of phages SPsP6 (SPs1121) and 315.1 (spyM3_0731), and between the hydrase genes of phages SPsP5 (SPs0933) and 315.2 (spyM3_0922), respectively (Fig. 4C).

Rearrangements are also found between SPs0933 of SPsP5 and spyM18_0777 of $\phi$ SpeC in MGAS8232, and SPs1118 of SPsP6 and spyM18_1237 of $\phi$ SpeA in MGAS8232. To clarify the genomic recombination in these sites, we further compared the genomic sequences of streptococcal phages by dotplot analysis (Fig. 5). Interestingly, about 8-10 kb of the SPsP5 


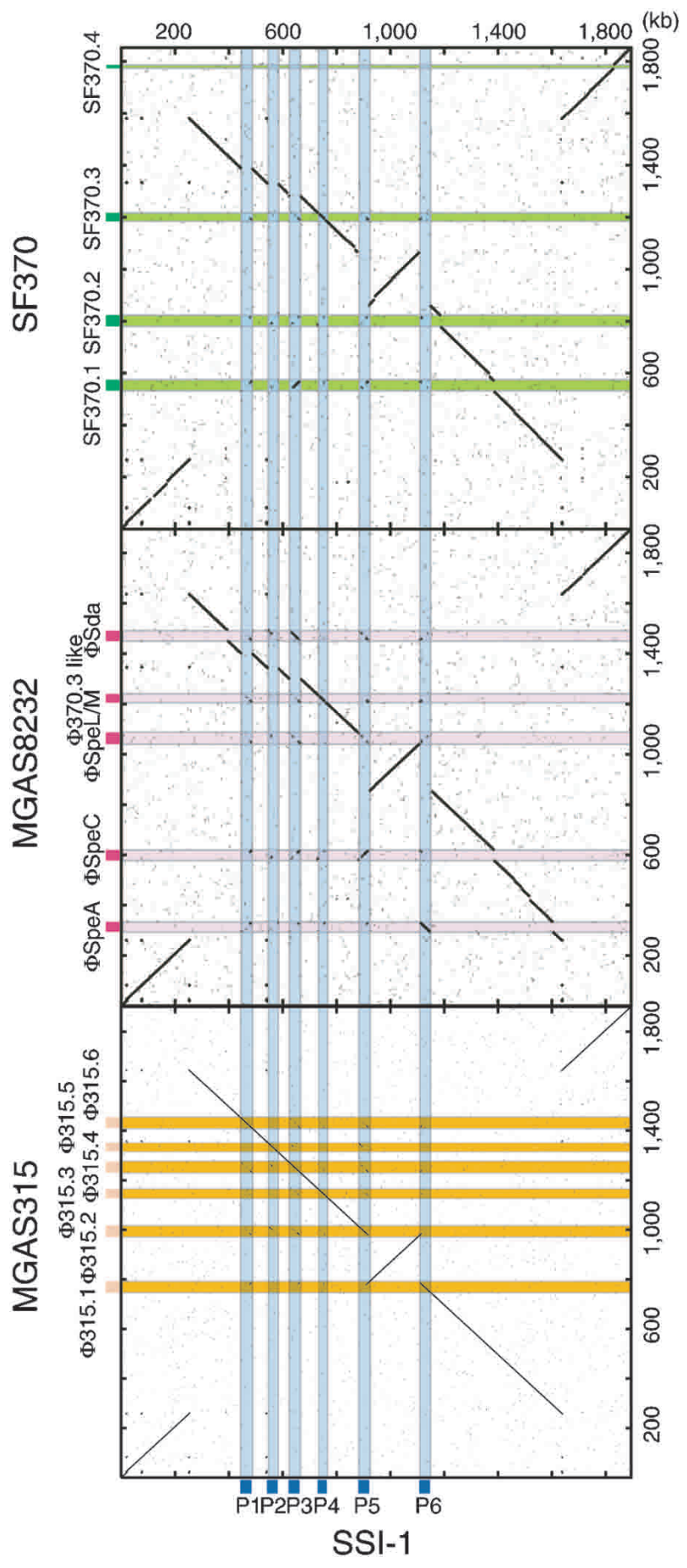

Figure 2 Comparison of the three sequenced GAS genomes based on the chromosomal organization of strain SSI-1. Dot-plot analyses were performed based on the genomic sequence of strain SSI-1 and the other three GAS strains (SF370, MGAS8232, and MGAS315). Deflection of segments along either axis indicates insertions of DNA segments. Segments not aligning along the diagonal line represent sequences that are similar but located in different parts of the genomes. Light blue, SSI-1-specific phages; pink, MGAS8232-specific phages; light green, SF370-specific phages; light orange, MGAS315specific phages. and SPsP6 phage regions near the attP-R sites are similar to those of other GAS phages. Therefore, genomic rearrangements in these regions might occur by homologous recombination of this region. However, in strain SF370, two phages in these regions should be excised. It is still unclear why homologous recombination of the $r r n$-comX region induces homologous recombination around the ter region. In comparative studies of Salmonella genomes, the orientation of the ter region did not affect chromosomal stability (Liu and Sanderson 1995; Hoskins et al. 2001; Makino and Suzuki 2001). On the other hand, the orientation of the ter region is thought to be important for chromosomal segregation in Escherichia coli (Perals et al. 2001). The orientation of the ter region in the GAS genome might be important to stabilize chromosomal segregation.

\section{Comparison of the Genes in Strain SSI-1 and Strains SF370 and MGAS8232}

Of the 1528 SSI-1 ORFs without phage-related genes, 1426 are common to all three strains. Most vegetative growth-related genes are included among the genes shared by the three GAS strains, and most of these genes are highly conserved, as revealed by SNP analysis (Table 1). As reported previously, strain SSI-1 also lacks tricarboxylic acid cycle and electron transport genes (Ferretti et al. 2001; Smoot et al. 2002). Of the other 102 ORFs, 38 are specific to SSI-1, 19 are shared by SSI-1 and SF370, and 45 are shared by SSI- 1 and MGAS8232.

\section{Comparison of the Genes in Strain SSI-1 and Strain MGAS315}

The gene contents of strain SSI- 1 and strain MGAS315 are almost completely conserved as revealed by the SNP analysis (Table 1). These two strains belong to serotype M3, and were isolated from STSS patients in different countries. However, 44 genes were found to be different between the strains, with silent SNPs (sSNP) or coding SNPs (cSNP; Table 2). Of them, eight have two or more amino acid changes per gene, and consist of four hypothetical proteins, a putative domain protein (SPs0659), two transcriptional regulators (SPs0776 and SPs1742), and putative UDP-glucose 6-dehydrogenase (hasC; SPs1848). Recent epidemiological studies using PFGE or multilocus sequence typing for housekeeping genes indicated that clinical isolates of invasive M3 strains were composed of multiple clones. However, there is no clear evidence for an increased propensity of some M3 clones to be associated with invasive infections, compared with M3 clones prevalent in the general population (Enright et al. 2001; Johnson et al. 2002). Our genetic information will be useful for future epidemiological studies to analyze the temporal and geographic distributions of invasive M3 strains, because nonsynonymous changes in chromosomal proteins (SPs0659, SPs0776, SPs1742, and SPs1848) can be used for these studies.

\section{Virulence Factors}

Most of the genes for known virulence factors are highly conserved in these strains (E values $>1.0 \times 10^{-80}$ ) except for phage-related genes (Table 3). Genes encoding four superantigens (SPs0161, 0560, 0657, and 1119) and three streptodornase genes along with those for mitogenic factors SPs0455, 0700, and 1743 were found in the SSI- 1 genome. We also found 22 genes predicted to encode extracellular proteins containing the LPXTG motif or other tripartite cell-wall anchor motif (Janulczyk and Rasmussen 2001). These genes are

\section{Genome Research


A

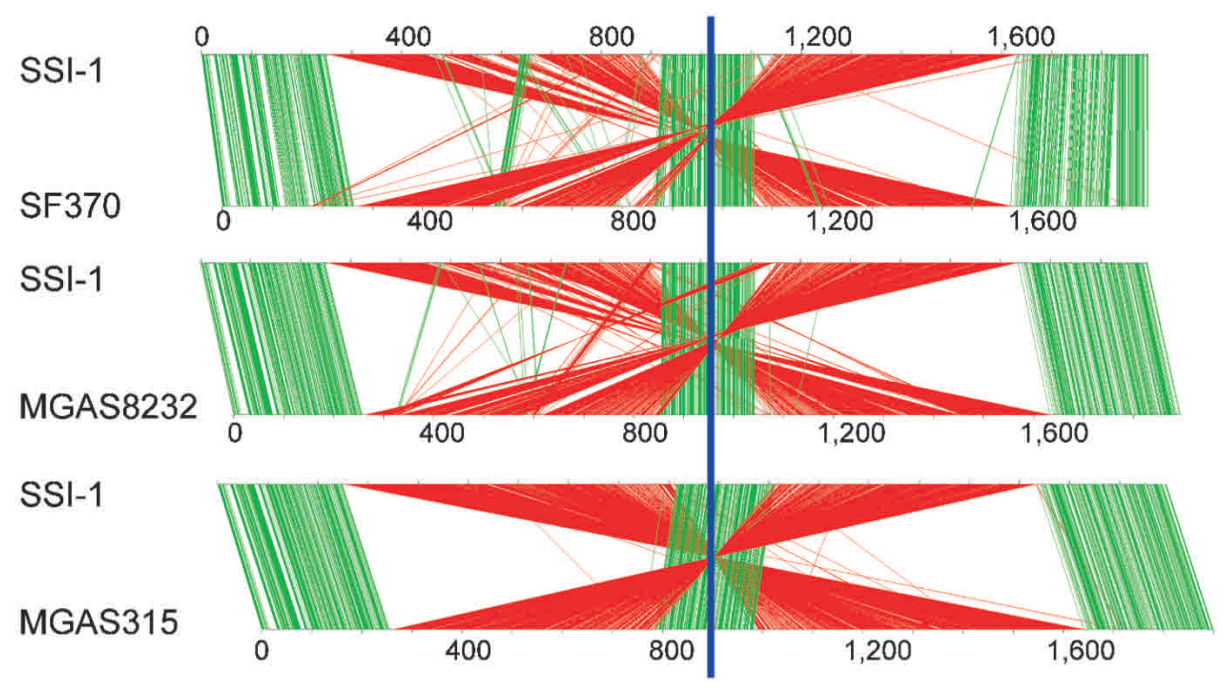

B

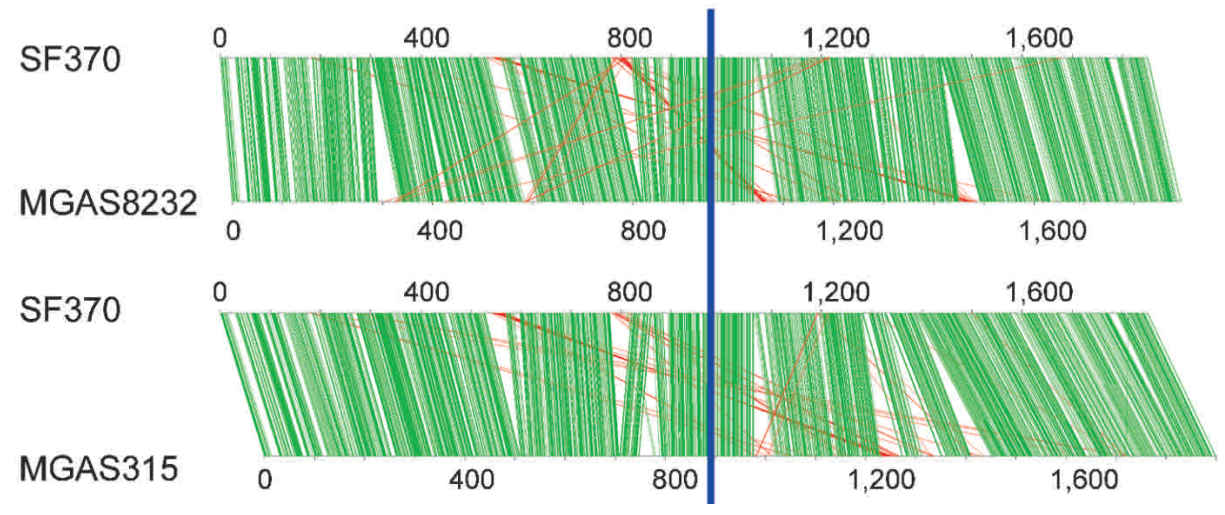

Figure 3 (Continued on next page)

also conserved among the four strains except for the genes for $\mathrm{M}$ protein, fibronectin-binding protein, and $s c l$ protein (Suppl. Table A). Genes for C5a peptidase, streptolysin O, and streptolysin $\mathrm{S}$ are well conserved (Table 3). These virulence factors are thought to influence the pathogenicity of GAS infections. However, no clear genetic variation in these genes was found. Therefore, the effects of these genes in severe GAS infection may arise from the regulation of gene expression (Cunningham 2000). In contrast, the genes for collagen-like proteins (SclA and SclB), Nra (Podbielski et al. 1999), Cpa, and fibronectin binding protein (F2-like protein) shared homology; however, these genes have different characteristics in each M-type strain. In particular, nra (SPs0099) and lepA (SPs0101) show significantly higher sSNPs and cSNPs (337 and 135 bases, respectively) compared with the average sSNPs (6.4 bases) and cSNPs (5.13 bases) in strains SSI- 1 and SF370.

The gene for PrtF2-like protein (SPs0106) is conserved among strains SSI-1, MGAS315, and MGAS8232, although nra is disrupted in MGAS8232. The nra-lepA region had already been reported as the fibronectin- and collagen-binding proteins and $\mathrm{T}$ antigen (FCT) region, with an extensive intergenomic recombination site (Bessen and Kalia 2002). Such genetic variation also occurs in the $m g a$-regulon, which includes the gene for M protein. All genes in both regions are thought to play important roles in the adherence and invasion of this organism (Cunningham 2000). This genetic diversity of adhesive molecules may reflect the types of diseases caused by this organism and their relative incidence. On the other hand, the other ORFs encoding cell-anchor motifs found in grampositive pathogenic bacteria are conserved among the four strains of GAS (Suppl. Table A; Navarre and Schneewind 1999; Janulczyk and Rasmussen 2001). Most of them encode proteins with enzymatic properties, indicating that these genes might be important in modulating other cell surface proteins, or in the acquisition of nutrients. Therefore, these genes are highly conserved in all GAS strains.

\section{Streptococcal Phages Exchange Their Virulent Cassettes by Genomic Rearrangement}

In contrast to the putative virulence factors, the gene contents of phages are variable among different serotypes of GAS organisms. Six regions of the genome of strain SSI-1 are composed of phage or phage-like elements, and they are almost completely conserved in strain MGAS315, serotype M3. Two phage regions in SSI-1 identified as SPsP1 and SPsP2, which are identical to phages $\phi 315.6$ and $\phi 315.5$, respectively, are specific for serotype M3 strains. SPsP5 is almost identical to 
C

S. pyogenes SSI-1 vs S. pneumoniae

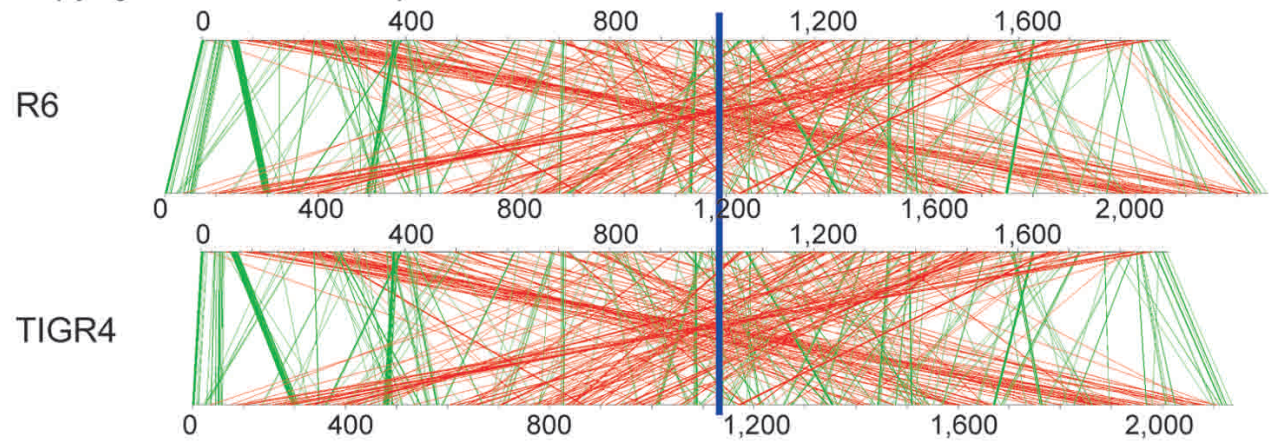

S. pyogenes SF370 vs S. pneumoniae

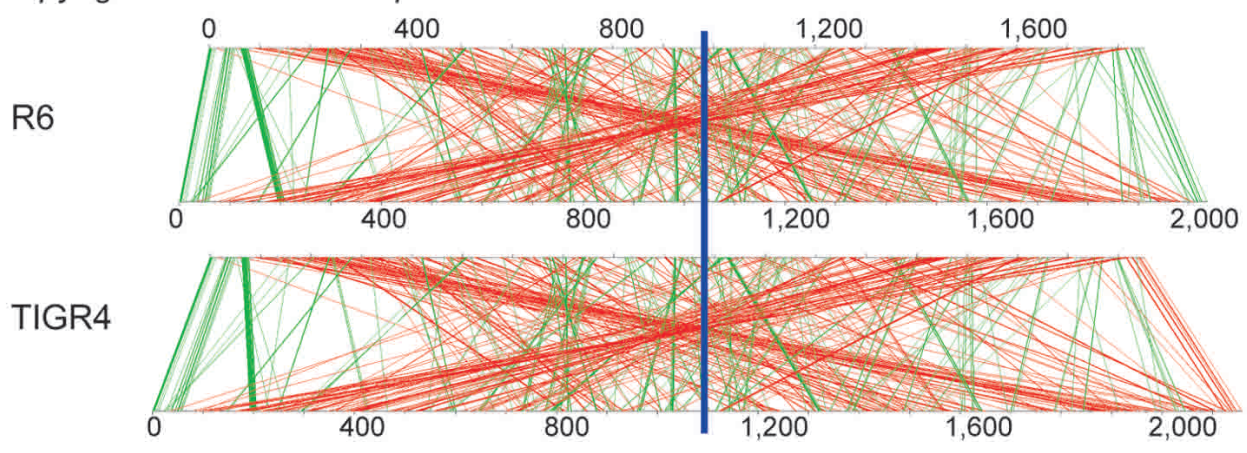

S. pyogenes SSI-1 vs S. agalactiae $2603 \mathrm{~V} / \mathrm{R}$

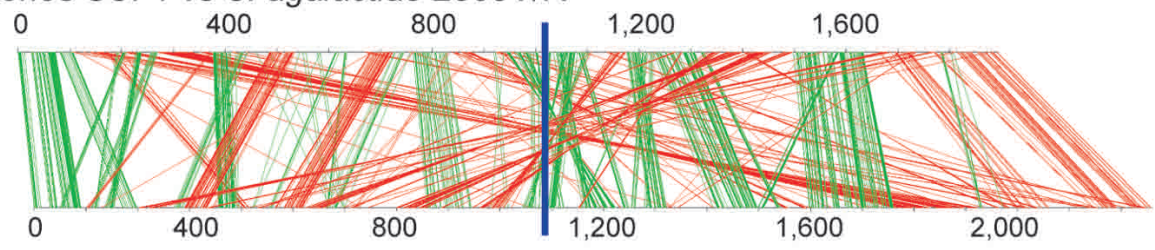

S. pyogenes SF370 vs S. agalactiae 2603 V/R

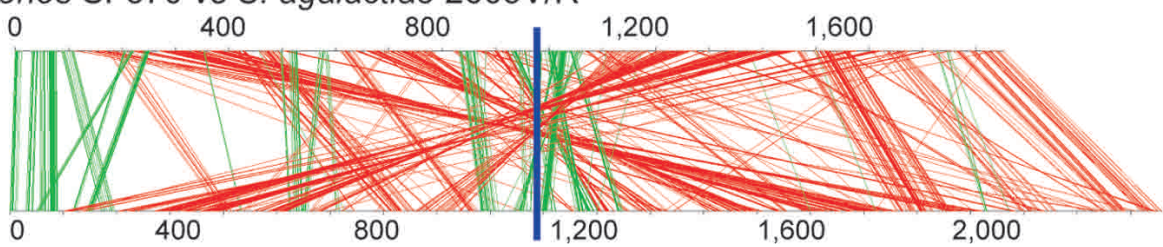

Figure 3 Comparison of genomic location of the homologous ORFs in GAS strains SSI-1 (M3) vs. SF370 (M1), SSI-1 vs. MGAS8232 (M18), and SSI-1 vs. MGAS315 (M3) (A), in GAS strains SF370 (M1) vs. MGAS8232 (M18) and SF370 vs. MGAS315 (M3) (B), in GAS strains and Streptococcus pneumoniae $(C)$, or $S$. agalactiae $2603 \mathrm{~V} / \mathrm{R}(D)$. Pairs of homologous ORFs between two strains were generated by BLASTP analysis $\left(\mathrm{E}<1.0 \times 10^{-5}\right)$. The homologous ORFs on each chromosome are shown by connected green lines (the relative location of each ORF is conserved) or red lines (the relative location of each ORF is in the opposite direction). The blue line indicates the putative region of the replication terminus (ter).

$\phi 315.2$ in MGAS315, and thus, this phage is also specific for M3 strains. Dot-plot analysis revealed that the last one-fourth of phage regions near the attP-R site are more similar to those of other phages (Fig. 5) than other regions of the phage sequences, even though these phages are only found in M3 strains. Interestingly, the streptococcal superantigen (SSA) gene in phage SPsP6 in strain SSI-1 is not found in the $\phi 315.1$ region, and is translocated to $\phi 315.2$ in strain MGAS315 (Fig. $3 \mathrm{C})$. It is noted that the virulence genes encoding the superantigens, hyaluronidases and streptodornases, which are pre- dicted as major virulence factors, are included in this region. These observations indicate that the virulence genes within the phage regions, which are a "streptococcal virulence cassette", are exchangeable if these phages are integrated in sites equidistant from the ter region (Fig. 6). Therefore, our genomic analyses clearly reveal an evolutionary mechanism for GAS phages.

We found that the holin genes, which are located near the attP-R site and found in the recombination site between SPsP5 and SPsP6, are classified by phylogenetic analysis into

\section{Genome Research}


A

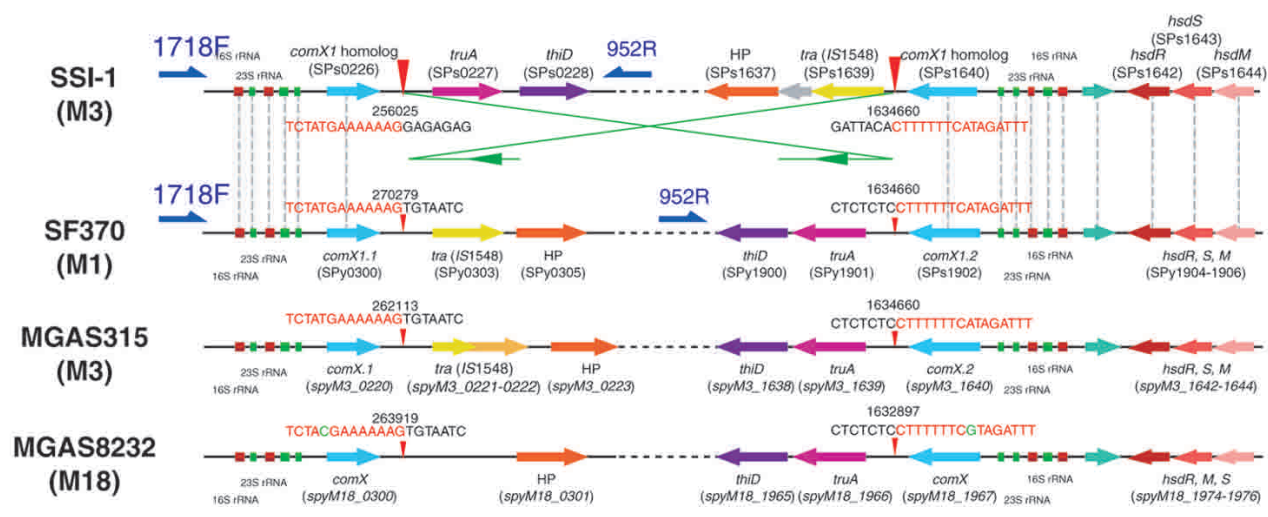

B Long PCR

(1718Fx952R)

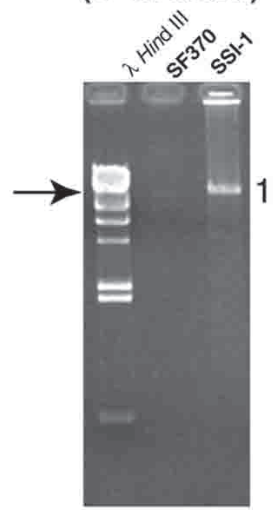

C
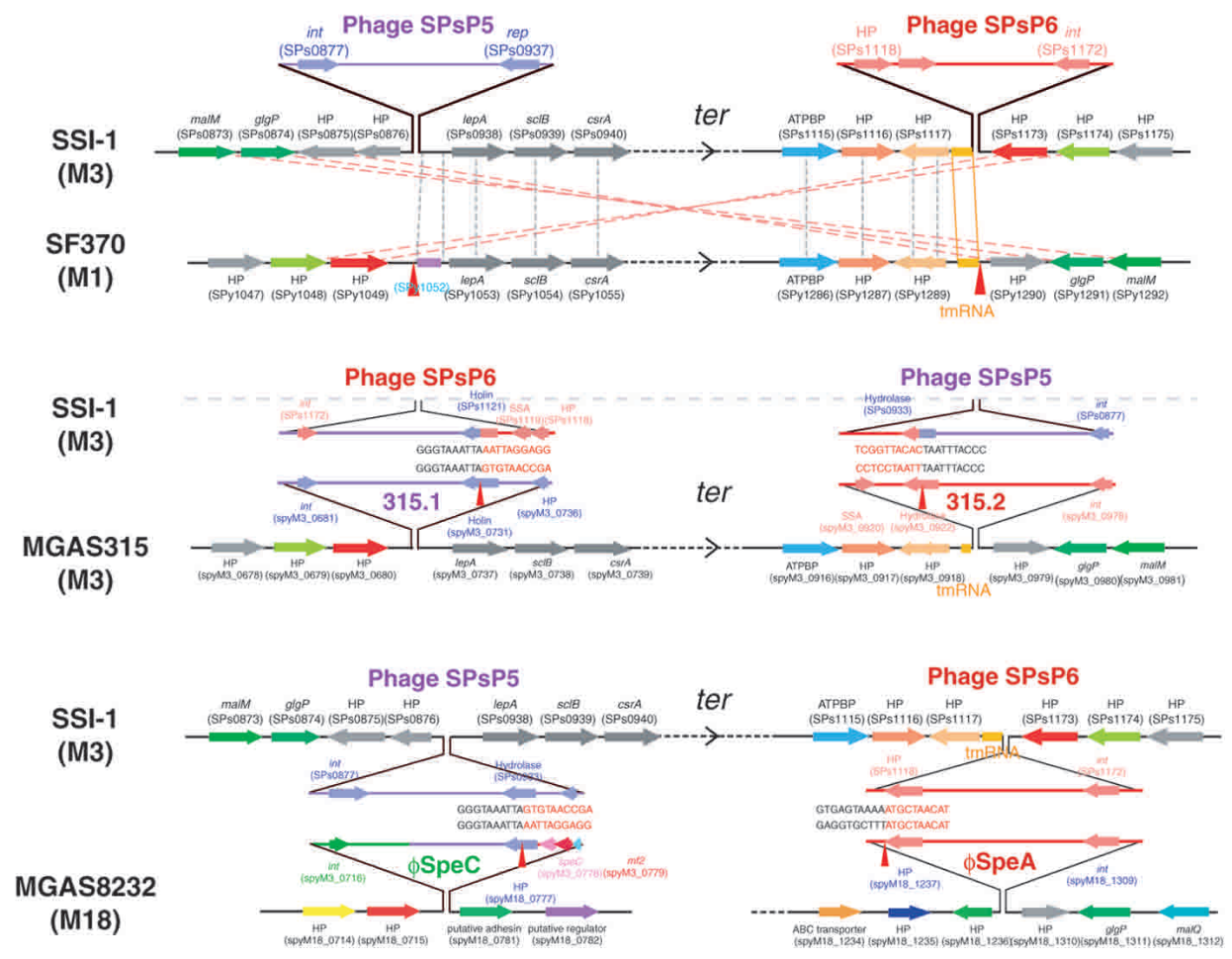

Figure 4 Expanded views of the $r r n-\operatorname{com} X$ genomic rearrangement site between strain SSI- 1 and other GAS strains. ( $A$ ) Comparison of $r r n-c o m X$ region in strain SSI-1 and strains SF370, MGAS315, or MGAS8232. HP, hypothetical protein. Red arrowheads indicate the rearrangement break-point in strain SSI-1, and green lines and arrows indicate the orientation of the rearrangement in strain SSI-1 compared with strain SF370. Gray dotted lines indicate orthologous genes that are located in relatively identical positions. (B) Long-PCR analysis of $r r n$-comX rearrangement site. Long-PCR was performed with PCR primers $1718 \mathrm{~F}$ and $952 \mathrm{R}$, and analyzed by agarose gel electrophoresis. (C) Expanded views of the phage rearrangement site between strain SSI-1 and other GAS strains. The gene order and sequences of the rearrangement sites of strain SSI-1 are compared with those of strains SF370, MGAS315, and MGAS8232 with MUMmer and CLUSTALW programs. Arrows represent the relative orientation of the genes. HP, hypothetical protein. Red arrowheads: The rearrangement break-point in strain SSI-1. Gray and pink dotted lines indicate the orthologous genes that are located in relatively identical positions or in the inverted chromosomal regions, respectively.

one major group (including 12 of 15 holin homologs in GAS phages) and two minor groups. The integrase genes, however, are divergent and are classified into five major lineages based on their amino acid sequences (Suppl. Fig. B). In addition, the 12 homologous holin genes are highly or completely conserved, despite more than 100 members of the holin gene family having been identified, defining more than 30 orthologous groups (Wang et al. 2000). The sequence similarities of the last one-fourth of the phage region in GAS phages may trigger not only the mechanism of homologous recombination in the GAS chromosome, but also contribute to the diversity of the distribution of superantigens or other virulence factors encoded in phage regions. Collectively, streptococcal phages are important contributors to genetic diversity, not only by inducing genomic rearrangements, but also by being a source of new genes. 


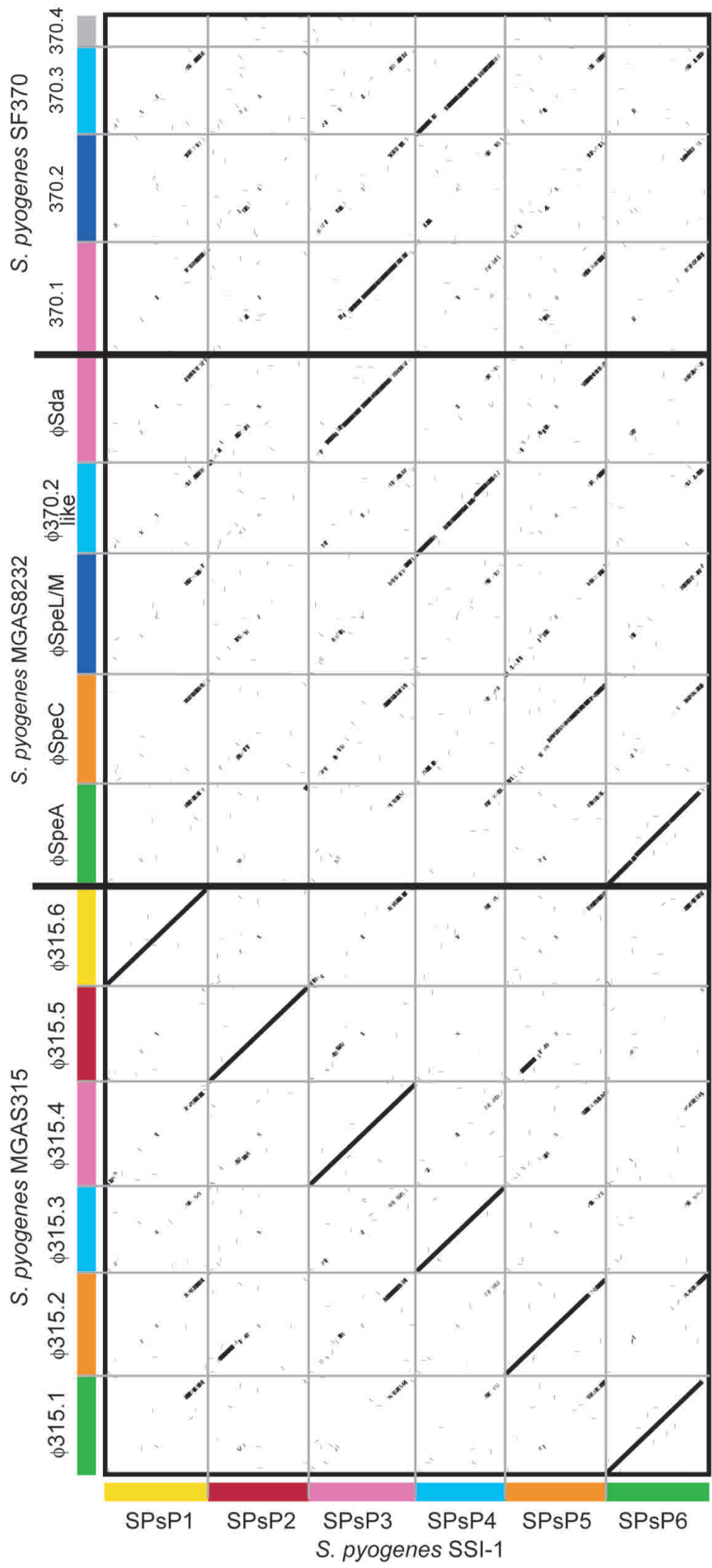

\section{GAS Pathogenicity and Genomic Rearrangement}

We also examined whether the genomic rearrangement is specific for strain SSI-1 or common to GAS strains. We analyzed the rearrangement in the $r r n$-com $X$ region (Suppl. Fig. A) by longPCR with clinical isolates from diverse localities. We divided these test strains into three groups: (A) strains isolated before 1985, (B) strains isolated from STSS patients after 1990 in Japan, and (C) strains isolated from non-STSS patients after 1990 in Japan. As shown in Supplemental Figure A, the typical genomic rearrangement in the rrn$\operatorname{com} X$ region was observed in $81 \%(35 / 43)$ of strains isolated from STSS patients after 1990. In contrast, the genetic rearrangement was observed in only $25 \%(7 / 28)$ of strains isolated before 1985 . Moreover, $57 \%$ of clinical strains (29/ 51) isolated from non-STSS patients after 1990 showed the rearrangement in this region. These results suggest that the genomic rearrangement in this region has occurred in many GAS strains with different $\mathrm{M}$ serotypes in the past. We note that almost all strains of serotypes M1, M3, and M28 from STSS patients have the rearrangement in the rrn-comX region. These observations may indicate that the X-shaped rearrangement found in strain SSI-1 was present in the recent past. This genomic rearrangement occurs in different M serotypes of GAS strains in recent isolates, and the phenomenon is becoming increasingly evident. Surprisingly, the increase in X-rearranged strains seems to coincide with the recent resurgence of rheumatic fever and severe invasive infections in Japan. It is possible that the resurgence of severe GAS infection is related to the clonal expansion of such invasive strains.

In conclusion, our results provide new insight into phage evolution as well as a mechanism for the origin of new clones and genetic variation in GAS. In a comparison of the genomes of three different serotype strains and the same serotype strains of GAS, we observed that the genetic variation of GAS was affected, not only by the integration of phages, but also by a large-scale genomic rearrangement of its chromosome. In addition, the genetic diversity of the GAS chromosome in phage regions might be induced by "virulence cassette" shuffling followed by genomic rearrangement. There remain more questions than answers regarding how these genomic rearrangements affect the gene expression and pathogenicity of GAS. We believe that this genetic information will assist in gaining

Figure 5 Dot-plot analysis of the six phages in strain SSI-1 with those in strain SF370 (M1), MGAS8232 (M18), and MGAS315 (M3). All phage sequences were extracted from each genome sequence and aligned with the integrase genes as the starting position. Homologous phage sequences are indicated in the same axis color. The width of each column corresponds to relative phage length. 
Table 2. Comparison of SSNP and CSNP in M3 Invasive Strains Isolated in Japan and the United States

\begin{tabular}{|c|c|c|c|c|c|c|}
\hline \multicolumn{2}{|c|}{ ORF number } & \multirow[b]{2}{*}{ Gene description } & \multirow{2}{*}{$\begin{array}{c}\text { Amino acids } \\
\text { Length }^{a}\end{array}$} & \multirow[b]{2}{*}{ sSNPs $^{b}$} & \multirow[b]{2}{*}{$\operatorname{cSNPs}^{c}$} & \multirow{2}{*}{$\begin{array}{c}\text { Amino acids } \\
\text { Changes } \\
\text { (per gene) }\end{array}$} \\
\hline SSI-1 & MGAS315 & & & & & \\
\hline sps0659 & spyM3_1583 & putative domain protein & 96 & 17 & 128 & 69 \\
\hline sps0553 & spyM3_1210 & hypothetical protein (phage associated) & 140 & 17 & 134 & 66 \\
\hline sps0135 & spyM3_0131 & hypothetical protein & 109 & 21 & 103 & 52 \\
\hline sps0510 & spyM3_1353 & hypothetical protein & 35 & 2 & 11 & 7 \\
\hline sps0525 & sрyM3_1246 & hypothetical protein (phage associated) & 84 & 8 & 21 & 15 \\
\hline sps1399 & spyM3_0457 & conserved hypothetical protein & 50 & 2 & 7 & 3 \\
\hline sps 1398 & spyM3_0457 & conserved hypothetical protein & 190 & 0 & 7 & 4 \\
\hline sps0449 & spyM3_1416 & hypothetical protein (phage associated) & 146 & 1 & 2 & 2 \\
\hline sps0776 & spyM3_1089 & putative transcriptional regulator & 174 & 2 & 2 & 2 \\
\hline sps0450 & spyM3_1415 & hypothetical protein (phage associated) & 98 & 0 & 1 & 1 \\
\hline sps0119 & spyM3_0117 & putative $\mathrm{V}$-type $\mathrm{Na}^{+}$-ATPase subunit $\mathrm{E}$ & 105 & 0 & 1 & 1 \\
\hline sps 1742 & spyM3_1744 & putative transcription regulator & 281 & 0 & 2 & 2 \\
\hline sps0857 & spyM3_1001 & hypothetical protein & 150 & 0 & 1 & 1 \\
\hline sps0664 & spyM3_1198 & putative arginine repressor & 158 & 0 & 1 & 1 \\
\hline sps 1848 & spyM3_1852 & putative UDP-glucose 6-dehydrogenase & 403 & 0 & 3 & 2 \\
\hline sps 1358 & spyM3_0496 & putative proton-translocating ATPase, delta subunit & 179 & 0 & 1 & 1 \\
\hline sps0219 & spyM3_0213 & putative D,D-carboxypeptidase, penicillin-binding protein & 375 & 2 & 2 & 1 \\
\hline sps1618 & spyM3_0241 & putative cytoplasmic membrane protein & 186 & 0 & 1 & 1 \\
\hline sps0043 & spyM3_0041 & $50 S$ ribosomal protein $\mathrm{L} 4$ & 208 & 0 & 1 & 1 \\
\hline sps 1128 & spyM3_0724 & hypothetical protein & 206 & 0 & 1 & 1 \\
\hline sps1645 & spyM3_1645 & putative response regulator (salivaricin regulon) & 202 & 0 & 1 & 1 \\
\hline sps 1124 & spyM3_0728 & hypothetical protein (phage associated) & 211 & 0 & 1 & 1 \\
\hline sps1615 & spyM3_0244 & putative two-component response regulator (CsrR/CovR) & 229 & 0 & 1 & 1 \\
\hline sps0879 & spyM3_0977 & putative repressor protein & 237 & 0 & 1 & 1 \\
\hline sps0322 & spyM3_1544 & putative transcriptional pleiotropic repressor & 261 & 0 & 1 & 1 \\
\hline sps0778 & spyM3_1087 & putative formate dehydrogenase & 295 & 0 & 1 & 1 \\
\hline sps 1442 & spyM3_0413 & putative prolipoprotein diacylglycerol transferase & 260 & 0 & 1 & 1 \\
\hline sps0448 & spyM3_1417 & hypothetical protein (phage associated) & 274 & 0 & 1 & 1 \\
\hline sps0385 & spyM3_1482 & putative tagatose 1,6-diphosphate aldolase & 326 & 0 & 1 & 1 \\
\hline sps0455 & spyM3_1409 & putative sdalpha deoxyribonuclease & 329 & 3 & 1 & 1 \\
\hline sps1191 & spyM3_0662 & putative acetoin dehydrogenase (TPP-dependent) beta chain & 360 & 0 & 1 & 1 \\
\hline sps 1858 & spyM3_1862 & putative transposase & 329 & 0 & 1 & 1 \\
\hline sps1068 & spyM3_0868 & putative lipoprotein & 351 & 0 & 1 & 1 \\
\hline sps0010 & spyM3_0009 & hypothetical protein & 429 & 0 & 1 & 1 \\
\hline sps0535 & spyM3_1326 & conserved hypothetical protein & 430 & 0 & 1 & 1 \\
\hline sps0743 & spyM3_1121 & putative structural protein (phage associated) & 423 & 0 & 1 & 1 \\
\hline sps 1420 & spyM3_0435 & putative peptidoglycan branched peptide synthesis protein & 409 & 0 & 1 & 1 \\
\hline sps0358 & spyM3_1509 & conserved hypothetical protein & 487 & 1 & 1 & 1 \\
\hline sps0669 & spyM3_1193 & conserved hypothetical protein & 498 & 0 & 1 & 1 \\
\hline sps0835 & spyM3_1025 & putative PBP 5 synthesis repressor & 484 & 0 & 1 & 1 \\
\hline sps0974 & spyM3_0774 & conserved hypothetical protein & 511 & 0 & 1 & 1 \\
\hline sps 1047 & spyM3_0847 & putative $A B C$ transporter (ATP-binding protein) & 515 & 0 & 1 & 1 \\
\hline sps 1067 & spyM3_0867 & putative sugar $A B C$ transporter (ATP-binding protein) & 511 & 0 & 1 & 1 \\
\hline sps1454 & spyM3_0401 & putative signal recognition particle (docking protein) & 517 & 0 & 1 & 1 \\
\hline sps1614 & spyM3_0245 & putative two-component sensor histidine kinase (CsrS/CovS) & 501 & 0 & 1 & 1 \\
\hline sps0772 & spyM3_1093 & putative heavy metal-transporting ATPase & 621 & 0 & 1 & 1 \\
\hline sps0790 & spyM3_1073 & putative competence protein & 748 & 0 & 1 & 1 \\
\hline sps 1228 & spyM3_0625 & putative DNA topoisomerase IV, subunit C & 822 & 0 & 1 & 1 \\
\hline sps0077 & spyM3_0076 & putative DNA-dependent RNA polymerase beta prime subunit & 1199 & 0 & 1 & 1 \\
\hline sps0576 & spyM3_1285 & putative beta-galactosidase & 1169 & 0 & 1 & 1 \\
\hline sps1292 & spyM3_0562 & putative carbamoylphosphate synthetase & 1059 & 0 & 1 & 1 \\
\hline
\end{tabular}

${ }^{a}$ Amino acids length in strain SSI- 1 .

bSNPs in orthologous genes of strain SSI-1 were compared with those of strain MGAS315. sSNP and ' ${ }^{\mathrm{C} S N P}$ indicate silent SNP and coding SNP (bp).

new insights into the molecular pathogenesis of GAS infection.

\section{METHODS}

\section{Bacterial Strains}

Streptococcus pyogenes strain SSI-1 was isolated in Japan in 1994 from a patient with STSS. This strain can induce necrotizing fasciitis in a mouse infection model (Okamoto et al. 2003). It produces pyrogenic exotoxins $\mathrm{A}(\mathrm{SpeA})$ and $\mathrm{B}(\mathrm{SpeB})$, and its serotype was determined to be M3 by sequence analysis of the emm gene of the organism (Murakami et al. 2002). Other clinical isolates and laboratory strains were isolated at Tokyo Women's Medical School, Nagoya University, Saga Prefectural Institute of Public Health, Ehime Prefectural Institute of Public Health, Osaka Prefectural Institute of Public Health, and the National Institute of Infectious Diseases, Japan. These strains were selected from our culture collection and checked for gene content, the production of putative exotoxins, emm 
Table 3. Comparison of Putataive and Predicted Virulence Factors in Four Strains of GAS Genomes

\begin{tabular}{|c|c|c|c|c|c|}
\hline \multirow[b]{2}{*}{ Gene description } & \multicolumn{4}{|c|}{ Strains } & \multirow[b]{2}{*}{ Location } \\
\hline & $\begin{array}{l}\text { SSI-1 } \\
(s p s)^{\mathrm{a}}\end{array}$ & $\begin{array}{l}\text { SF370 } \\
(\text { spy })^{\mathrm{a}}\end{array}$ & $\begin{array}{l}\text { MGAS315 } \\
(\text { spyM3_) }\end{array}$ & $\begin{array}{l}\text { MGAS8232 } \\
(\text { (spyM18_) }\end{array}$ & \\
\hline \multicolumn{6}{|l|}{ Proteinase } \\
\hline C3 degrading proteinase & 0269 & 1851 & 1598 & 1914 & $\mathrm{Ch}$ \\
\hline Exfoliative toxin-like protein & 1220 & 0918 & 0632 & 0975 & $\mathrm{Ch}$ \\
\hline $\mathrm{IdeS} / \mathrm{Sib} 38$ & 1270 & 0861 & 0583 & 0921 & $\mathrm{Ch}$ \\
\hline Streptokinase A & 1700 & 1979 & 1698 & 2042 & $\mathrm{Ch}$ \\
\hline C5a peptidase & 1724 & 2010 & 1726 & 2074 & $\mathrm{Ch}$ \\
\hline SpeB/Cysteine proteinase & 1739 & 2039 & 1742 & 2099 & $\mathrm{Ch}$ \\
\hline Serine proteinase & 1860 & 2216 & 1864 & 2256 & $\mathrm{Ch}$ \\
\hline \multicolumn{6}{|l|}{ Adhesin } \\
\hline GRAB & 0828 & 1357 & 1032 & 1369 & $\mathrm{Ch}$ \\
\hline SClA & $(1704)^{c}$ & 1983 & $1702 / 1703$ & - & $\mathrm{Ch}$ \\
\hline $\mathrm{SClB}$ & 0939 & 1054 & 0738 & 1029 & $\mathrm{Ch}$ \\
\hline$M$ protein & 1725 & 2018 & 1727 & 2076 & $\mathrm{Ch}$ \\
\hline Fibronectin-binding protein F2-like & 0106 & - & 0104 & 0132 & $\mathrm{Ch}$ \\
\hline Fibronectin-binding protein (Fba)-like & - & 2009 & - & - & \\
\hline Internalin-like protein & 0825 & 1361 & 1035 & 1373 & $\mathrm{Ch}$ \\
\hline Laminin-binding protein & 1723 & 2007 & 1725 & 2073 & $\mathrm{Ch}$ \\
\hline \multicolumn{6}{|l|}{ Hemolysin } \\
\hline SLO & 0132 & 0167 & 0130 & 0165 & $\mathrm{Ch}$ \\
\hline SLS & 1366 & 0746 & 0488 & 0807 & $\mathrm{Ch}$ \\
\hline CAMP & 1104 & 1273 & 0905 & 1221 & $\mathrm{Ch}$ \\
\hline Hemolysin (hylA1) & 0709 & 1497 & 1153 & 1515 & $\mathrm{Ch}$ \\
\hline Hemolysin homolog (hylX) & 1583 & 0378 & 0276 & 0432 & $\mathrm{Ch}$ \\
\hline Hemolysin homolog (hyl III) & 1016 & 1159 & 0815 & 1119 & $\mathrm{Ch}$ \\
\hline \multicolumn{6}{|l|}{ Capsule synthesis and degradation } \\
\hline Hyalunonate synthase (hasA) & 1847 & 2200 & 1851 & 2236 & $\mathrm{Ch}$ \\
\hline Hyaluronidase & 0567 & 1600 & 1294 & 1606 & $\mathrm{Ch}$ \\
\hline Hyaluronidase & 0447 & - & 1418 & - & $\mathrm{Ph}$ \\
\hline Hyaluronidase & 1127 & - & 1418 & - & $\mathrm{Ph}$ \\
\hline Hyaluronidase & 0763 & - & 1108 & - & $\mathrm{Ph}$ \\
\hline Hyaluronidase & 0927 & - & 1101 & - & $\mathrm{Ph}$ \\
\hline Hyaluronidase (hylP1) & 0648 & 0701 & 1214 & - & $\mathrm{Ph}$ \\
\hline Hyaluronidase (hylP2) & - & 0997 & - & - & $\mathrm{Ph}$ \\
\hline Hyaluronidase (hylP3) & - & 1445 & - & - & $\mathrm{Ph}$ \\
\hline Hyaluronidase (hyl) & - & - & - & 0385 & $\mathrm{Ph}$ \\
\hline Hyaluronidase (hyl) & - & - & - & 0770 & $\mathrm{Ph}$ \\
\hline Hyaluronidase (hyl) & - & - & - & 1254 & $\mathrm{Ph}$ \\
\hline Hyaluronidase (hyl) & - & - & - & 1455 & $\mathrm{Ph}$ \\
\hline \multicolumn{6}{|l|}{ DNase } \\
\hline Mitogenic factor $(m f)$ & 1743 & 2043 & 1745 & 2104 & $\mathrm{Ch}$ \\
\hline Mitogenic factor-like & 0770 & - & 1095 & - & $\mathrm{Ph}$ \\
\hline MF2 (mf2) & - & 0712 & - & 0779 & $\mathrm{Ch}$ \\
\hline MF3 (mf3) & - & 1436 & - & - & $\mathrm{Ph}$ \\
\hline \multirow{2}{*}{\multicolumn{6}{|c|}{ Superantigen }} \\
\hline & & & & & \\
\hline SpeA & 0560 & - & 1301 & 0393 & $\mathrm{Ph}$ \\
\hline SpeC & - & 0861 & - & 0778 & $\mathrm{Ph}$ \\
\hline SpeG & 0161 & 0212 & 0155 & 0201 & $\mathrm{Ch}$ \\
\hline SpeH & - & 1008 & - & - & $\mathrm{Ph}$ \\
\hline Spel & - & 1007 & - & - & $\mathrm{Ph}$ \\
\hline Spel & - & - & - & 0919 & $\mathrm{Ch}$ \\
\hline SpeK & 0657 & - & 1205 & - & $\mathrm{Ph}$ \\
\hline SpeL $^{d}$ & 0657 & - & 1205 & $1 \overline{238}$ & $\mathrm{Ph}$ \\
\hline SpeM & - & - & & 1239 & $\mathrm{Ph}$ \\
\hline SmeZ & - & 1998 & - & 2064 & $\mathrm{Ch}$ \\
\hline SSA & 1119 & - & 0920 & - & $\mathrm{Ph}$ \\
\hline \multicolumn{6}{|l|}{ Immunoreactive antigen } \\
\hline Immunogenic secreted protein & 0305 & 1801 & 1562 & 1870 & $\mathrm{Ch}$ \\
\hline Myosin crossreactive antigen & 1525 & 0470 & 0332 & 0512 & $\mathrm{Ch}$ \\
\hline Immunogenic secreted protein & 1728 & 2025 & 1731 & 2082 & $\mathrm{Ch}$ \\
\hline \multicolumn{6}{|l|}{ Regulators } \\
\hline SpeB protease transcription regulator $(r g g)$ & 1742 & 2042 & 1744 & 2103 & $\mathrm{Ch}$ \\
\hline RopA (trigger factor) & 0232 & 1896 & 1634 & 1961 & $\mathrm{Ch}$ \\
\hline $\mathrm{M}$ protein transacting positive regulator & 1726 & 2019 & 1728 & 2077 & $\mathrm{Ch}$ \\
\hline $\operatorname{CsrR} / \mathrm{S}(\operatorname{CovR} / \mathrm{S})^{\mathrm{e}}$ & $1614 / 1615$ & 0337 & $0244 / 0245$ & $328 / 0329$ & $\mathrm{Ch}$ \\
\hline RofA & 0163 & 0216 & 0157 & 0205 & $\mathrm{Ch}$ \\
\hline
\end{tabular}

\section{Genome Research}


Table 3. Continued

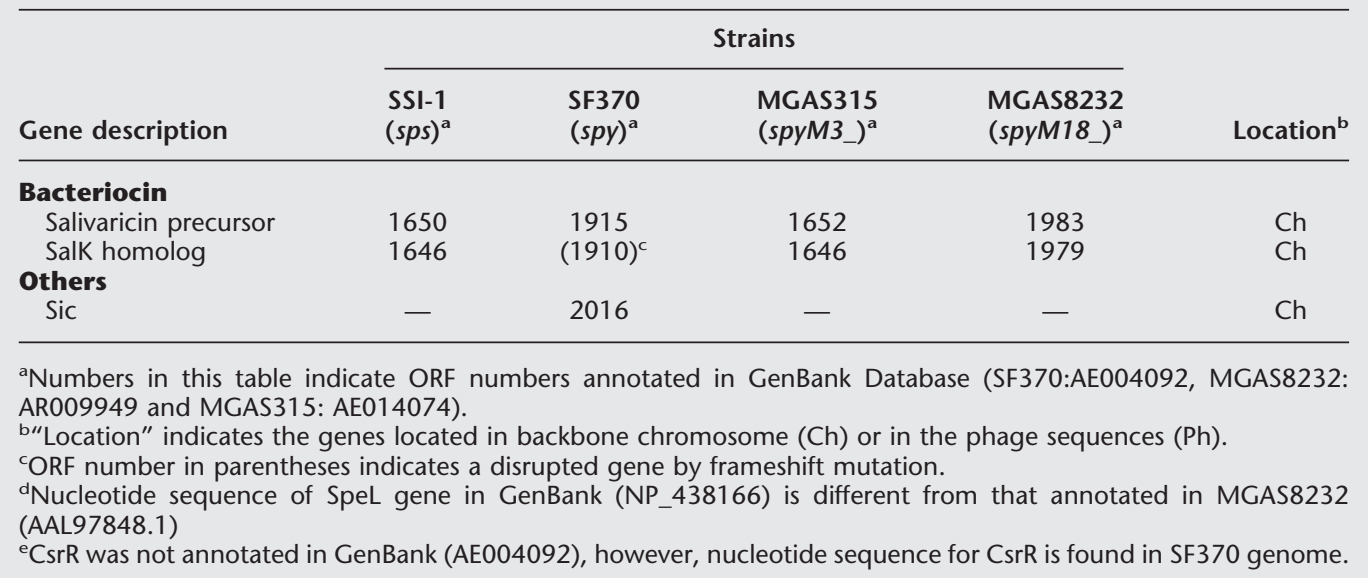

genotype, patient history, and the area of isolation recorded (Suppl. Table B).

\section{Restriction Analyses by PFGE and Construction of the Physical Map of Strain SSI-1}

We chose four restriction enzymes to construct the physical map of the strain SSI-1 genome. The restriction enzymes Sfil and SgrAI were selected according to the study of chromosomal DNA analysis of strain SF370 (Suvorov and Ferretti 1996). FseI and AscI were selected according to the nucleotide sequence of strain SF370 (GenBank accession no. AE004092), because they respectively result in only four or two fragments from the SF370 genome and three or three fragments from the SSI-1 genome. A total of 10 probes was selected from the predicted ORFs in the SF370 sequence (leuS, csrS, dinG, fbp54, cfa, dnaX, pbp2X, gyrA, speB, and recA), and these gene fragments were used for hybridization with PFGE restriction fragments (Suppl. Fig. C). Southern blotting was performed with digoxigenin-labeled probes according to the manufacturer's instructions (Roche Diagnostics).

\section{Genome Sequencing and Annotation}

The initial stage of sequencing was performed using wholegenome random shotgun methods with sheared chromosomal DNA from strain SSI-1. We constructed a pUC18-based library containing 1-2 kb and 4-5 kb inserts, and sequenced 48,000 clones (12.6-fold coverage) with Big-Dye terminator chemistry and an ABI 3700 sequencer (Applied Biosystems) and with ET-Dye terminator chemistry and a MegaBACE 1000 sequencer (Amersham Biosciences). The sequence was assembled using Phred/Phrap/Consed (Ewing and Green 1998; Ewing et al. 1998; Gordon et al. 1998). Gaps in the sequence were filled by direct PCR sequencing, using primers con-

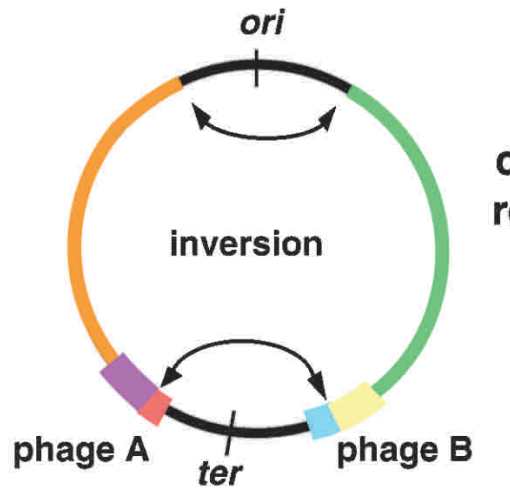

\section{chromosomal rearrangement}
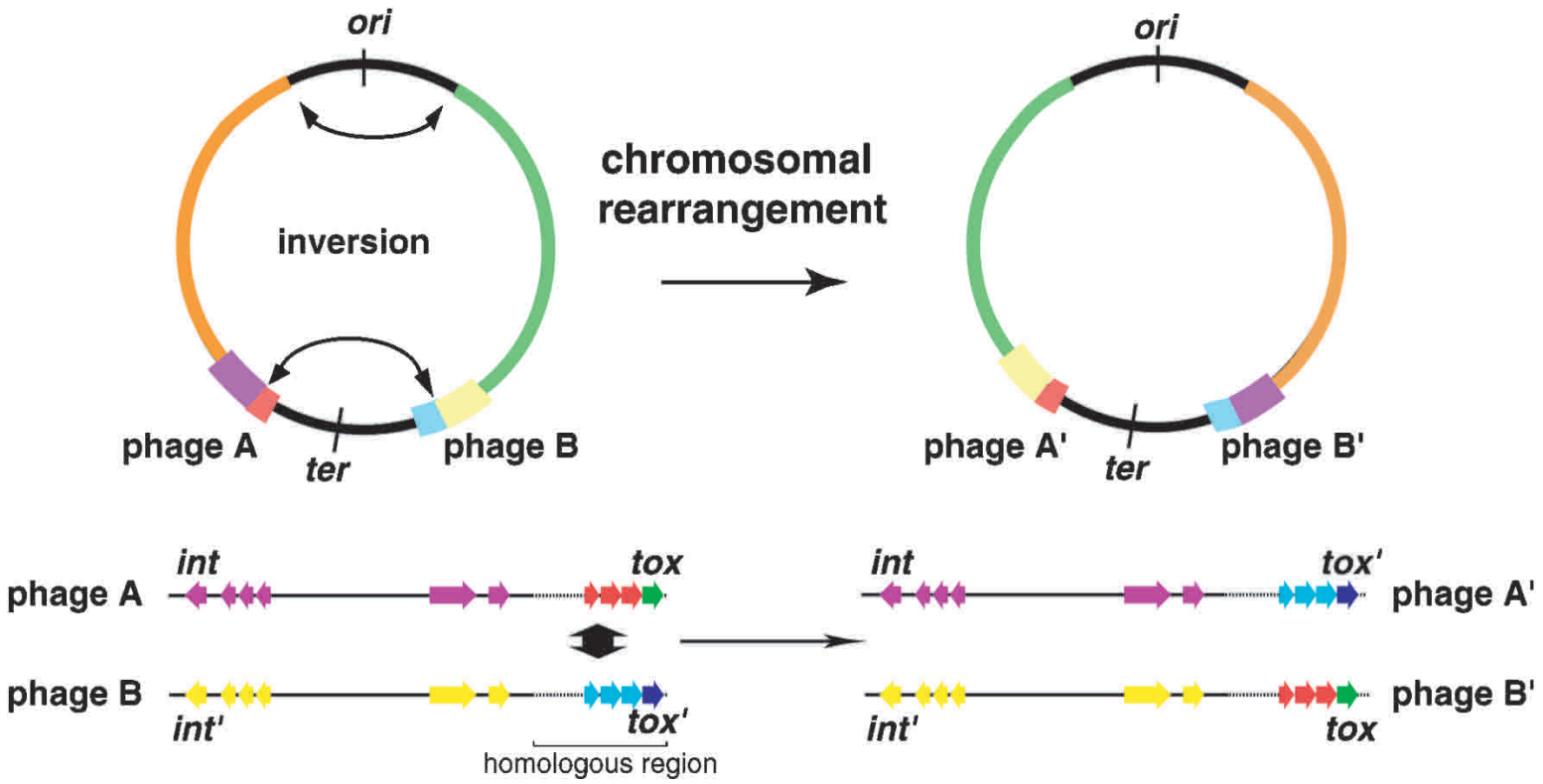

Figure 6 Schematic diagram of phage-related rearrangements by chromosomal inversion. Two phages integrated equidistant from the ter region exchange their virulent cassettes. int, integrase gene of phage region. tox indicates superantigen, mitogenic factor, or streptodornase genes. 
structed to anneal to each end of neighboring contigs. Finally, the entire sequence was estimated to have an error rate of less than 1 per 10,000 bases (Phrap score $\geq 40$ ). The final assembly was verified by the comparison of restriction-enzyme digest patterns using pulsed-field gel electrophoresis and Southern blot analysis with 40 specific genes as probes as described above. To verify and determine the assembled sequences, a total of 89 primer sets was constructed to cover whole chromosomal DNA of strain SSI-1 at the unique flanking sequence, and $18-25 \mathrm{~kb}$ of long-PCR was performed by the LA-PCR method (Takara). Large repeated elements in the genome (700-6000 bp) such as the $16 \mathrm{~S}$ and 23s rRNA operons (rrn) were amplified from chromosomal DNA using Ex-Taq or LA-Taq (Takara), sequenced, and assembled independently, as described above.

ORFs $>90 \mathrm{bp}$ were identified and annotated separately using Genome Gambler version 1.47 (Sakiyama et al. 2000) and GLIMMER 2 (Delcher et al. 1999a; www.tigr.org). The predicted ORFs were reviewed individually by a manual search for start codons on the basis of ribosomal-binding motifs. ORFs were further compared across a nonredundant protein database using BLASTP software (version 2.2.3; Altschul et al. 1997). Functional motifs and the domains of proteins were identified by searches against Prosite, Blocks, and Pfam database (http://www.sanger.ac.uk/Software/Pfam/ search.shtml) and phi-BLAST (http://www.ncbi.nlm. nih.gov/ BLAST/). Protein localization and transmembrane domains were predicted by combining PSORT with the rule set for gram-positive bacteria (http://psort.nibb.ac.jp/), and the SOSUI/SOSUI signal program (http://sosui.proteome.bio. tuat.ac.jp/sosuiframe0.html). Cell-wall attachment motifs (LPXTG) and secreted protein motifs (sortase recognition motif) were identified with the original Perl script (version 5.6). Functional categories based on the analysis of clusters of orthologous genes were assigned by using COGnitor (Tatusov et al. 2001) (http://www.ncbi.nlm.nih.gov/COG/xognitor.html). Transfer RNA genes were identified using tRNAscan-SE (Lowe and Eddy 1997).

\section{Comparative Genomes of Four GAS Strains and Determination of Genomic Rearrangement}

The genomic sequences of other $S$. pyogenes strains (SF370:AE004092, MAS8232: AR009949, and MGAS315: AE014074), S. pneumoniae (R6: AE007317 and TIGR4: AE005672), and $S$. agalactiae 2603V/R (AE009948) were obtained through the Web site of the National Center of Biological Information (NCBI, http://www.ncbi.nlm.nih.gov). Alignment of the complete genomic sequences of all four bacterial strains was accomplished with the MUMmer program (Delcher et al. 1999b), CONSERV (Goto et al. 2000), and FASTA3 (Pearson 1990). The predicted ORFs from these strains were aligned using BLASTP (maximum E-value $=10^{-5}$ ). Single nucleotide polymorphism (SNP) analysis was also performed with CLUSTALW (Thompson et al. 1994) for each orthologous gene. To compare the lineage of phage genes in the four GAS strains, predicted amino acids sequences in the four GAS strains were compared with CLUSTALW (DNA Data Bank of Japan), and the phylogenetic tree was constructed using the neighbor-joining method (Kumar et al. 2001) on MEGA2.1 software (http://www. megasoftware.net/). Rearrangement sites were verified by the LA-PCR method (Takara) using sitespecific primer pairs (rrn-comX region: 5'-TTGTCAAGAGCT TACTGACTGAGGCGACTGGGAC-3' and 5'-AGCGATACTA GATGCAAAAGTACAGCCTGCGCC- $3^{\prime}$ ). Briefly, PCR was performed as follows: $95^{\circ} \mathrm{C}$ for $1 \mathrm{~min}$ for one cycle, $98^{\circ} \mathrm{C}$ for 10 sec and $68^{\circ} \mathrm{C}$ for $20 \mathrm{~min}$ for 30 cycles, and $72^{\circ} \mathrm{C}$ for $10 \mathrm{~min}$ for one cycle. The amplified fragments were separated on $0.8 \%$ agarose gel electrophoresis and visualized by ethidium bromide staining.

\section{ACKNOWLEDGMENTS}

We thank T. Hayashi, T. Shimizu, and S. Kuhara for their advice, and N. Ogasawara and H. Yoshikawa for encouragement. We also thank K. Kikuchi, S. Murai, M. Ohta, T. Ikebe, and $\mathrm{H}$. Watanabe for providing clinical isolates of GAS. We also thank K. Oshima, K. Furuya, and C. Yoshino for technical assistance. This work was supported by the Research for the Future Program of the Japan Society for the Promotion of Science (JSPS-RFTFO0L01411).

The publication costs of this article were defrayed in part by payment of page charges. This article must therefore be hereby marked "advertisement" in accordance with 18 USC section 1734 solely to indicate this fact.

\section{REFERENCES}

Alm, R.A., Ling, L.S., Moir, D.T., King, B.L., Brown, E.D., Doig, P.C., Smith, D.R., Noonan, B., Guild, B.C., deJonge, B.L., et al. 1999. Genomic-sequence comparison of two unrelated isolates of the human gastric pathogen Helicobacter pylori. Nature 397: 176-180.

Altschul, S.F., Madden, T.L., Schaffer, A.A., Zhang, J., Zhang, Z., Miller, W., and Lipman, D.J. 1997. Gapped BLAST and PSI-BLAST: A new generation of protein database search programs. Nucleic Acids Res. 25: 3389-3402.

Bentley, R.W., Leigh, J.A., and Collins, M.D. 1991. Intrageneric structure of Streptococcus based on comparative analysis of small-subunit rRNA sequences. Int. J. Syst. Bacteriol. 41: 487-494.

Beres, S.B., Sylva, G.L., Barbian, K.D., Lei, B., Hoff, J.S., Mammarella, N.D., Liu, M.Y., Smoot, J.C., Porcella, S.F., Parkins, L.D., et al. 2002. Genome sequence of a serotype M3 strain of group A Streptococcus: Phage-encoded toxins, the high-virulence phenotype, and clone emergence. Proc. Natl. Acad. Sci. 99: $10078-10083$.

Bessen, D.E. and Kalia, A. 2002. Genomic localization of a T serotype locus to a recombinatoria zone encoding extracellular matrix-binding proteins in Streptococcus pyogenes. Infect. Immun. 70: $1159-1167$

Cole, S.T. 1998. Comparative mycobacterial genomics. Curr. Opin. Microbiol. 1: 567-571.

Cone, L.A., Woodard, D.R., Schlievert, P.M., and Tomory, G.S. 1987. Clinical and bacteriologic observations of a toxic shock-like syndrome due to Streptococcus pyogenes. N. Engl. J. Med. 317: 146-149.

Cunningham, M.W. 2000. Pathogenesis of group A streptococcal infections. Clin. Microbiol. Rev. 13: 470-511.

Delcher, A.L., Harmon, D., Kasif, S., White, O., and Salzberg, S.L. 1999a. Improved microbial gene identification with GLIMMER. Nucleic Acids Res. 27: 4636-4641.

Delcher, A.L., Kasif, S., Fleischmann, R.D., Peterson, J., White, O., and Salzberg, S.L. 1999b. Alignment of whole genomes. Nucleic Acids Res. 27: 2369-2376.

Eisen, J.A., Heidelberg, J.F., White, O., and Salzberg, S.L. 2000. Evidence for symmetric chromosomal inversions around the replication origin in bacteria. Genome Biol. 1: RESEARCH0011.

Enright, M.C., Spratt, B.G., Kalia, A., Cross, J.H., and Bessen, D.E. 2001. Multilocus sequence typing of Streptococcus pyogenes and the relationships between emm type and clone. Infect. Immun. 69: $2416-2427$

Ewing, B. and Green, P. 1998. Base-calling of automated sequencer traces using phred. II. Error probabilities. Genome Res. 8: 186-194.

Ewing, B., Hillier, L., Wendl, M.C., and Green, P. 1998. Base-calling of automated sequencer traces using phred. I. Accuracy assessment. Genome Res. 8: 175-185.

Ferretti, J.J., McShan, W.M., Ajdic, D., Savic, D.J., Savic, G., Lyon, K., Primeaux, C., Sezate, S., Suvorov, A.N., Kenton, S., et al. 2001. Complete genome sequence of an M1 strain of Streptococcus pyogenes. Proc. Natl. Acad. Sci. 98: 4658-4663.

Gordon, D., Abajian, C., and Green, P. 1998. Consed: A graphical tool for sequence finishing. Genome Res. 8: 195-202.

Goto, N., Kurokawa, K., and Yasunaga, T. 2000. CONSERV: A tool for finding exact matching conserved sequences in biological sequences. Genome Informatics 11: 307-308.

Holm, S.E., Kohler, W., Kaplan, E.L., Schlievert, P.M., Alouf, J.E., Stevens, D.L., and Kotb, M. 1997. Streptococcal toxic shock syndrome (STSS). An update: A roundtable presentation. Adv. Exp. Med. Biol. 418: 193-199.

Hoskins, J., Alborn Jr., W.E., Arnold, J., Blaszczak, L.C., Burgett, S.,

\section{Genome Research}


DeHoff, B.S., Estrem, S.T., Fritz, L., Fu, D.J., Fuller, W., et al. 2001. Genome of the bacterium Streptococcus pneumoniae strain R6. J. Bacteriol. 183: 5709-5717.

Hughes, D. 2000. Evaluating genome dynamics: The constraints on rearrangements within bacterial genomes. Genome Biol. 1: REVIEWS0006

Inagaki, Y., Myouga, F., Kawabata, H., Yamai, S., and Watanabe, H. 2000. Genomic differences in Streptococcus pyogenes serotype M3 between recent isolates associated with toxic shock-like syndrome and past clinical isolates. J. Infect. Dis. 181: 975-983.

Janulczyk, R. and Rasmussen, M. 2001. Improved pattern for genome-based screening identifies novel cell wall-attached proteins in gram-positive bacteria. Infect. Immun. 69: 4019-4026.

Johnson, D.R., Wotton, J.T., Shet, A., and Kaplan, E.L. 2002. A comparison of group A streptococci from invasive and uncomplicated infections: Are virulent clones responsible for serious streptococcal infections? J. Infect. Dis. 185: 1586-1595.

Kaplan, E.L. 1991. The resurgence of group A streptococcal infections and their sequelae. Eur. J. Clin. Microbiol. Infect. Dis. 10: $55-57$.

Kumar, S., Tanura, K., Jakobsen, I.B., and Nei, M. 2001. MEGA2: Molecular evolutonaty genetics analysis software. Bioinformatics 17: $1244-1245$.

Kuzminov, A. and Stahl, F.W. 1999. Double-strand end repair via the RecBC pathway in Escherichia coli primes DNA replication. Genes \& Dev. 13: 345-356.

Leach, D.R., Okely, E.A., and Pinder, D.J. 1997. Repair by recombination of DNA containing a palindromic sequence. Mol. Microbiol. 26: 597-606.

Liu, G.R., Rahn, A. Liu, W.Q., Sanderson, K.E., Johnston, R.N., and Liu, S.L. 2002. The evolving genome of Salmonella enterica serovar Pullorum. J. Bacteriol. 184: 2626-2633.

Liu, S.L. and Sanderson, K.E. 1995. Rearrangements in the genome of the bacterium Salmonella typhi. Proc. Natl. Acad. Sci. 92: 1018-1022.

Lowe, T.M. and Eddy, S.R. 1997. tRNAscan-SE: A program for improved detection of transfer RNA genes in genomic sequence. Nucleic Acids Res. 25: 955-964.

Maeder, D.L., Weiss, R.D., Dunn, D.M., Cherry, J.L., Gonzalez, J.M., DiRuggiero, J., and Robb, F.T. 1999. Divergence of the hyperthermophilic archaea Pyrococcus furiosus and P. horikoshii inferred from complete genomic sequences. Genetics 152: $1299-1305$

Makino, S. and Suzuki, M. 2001. Bacterial genomic reorganization upon DNA replication. Science 292: 803a.

McShan, W.M., Tang, Y.F., and Ferretti, J.J. 1997. Bacteriophage T12 of Streptococcus pyogenes integrates into the gene encoding a serine tRNA. Mol. Microbiol. 23: 719-728.

Murakami, J., Kawabata, S., Terao, Y., Kikuchi, K., Totsuka, K., Tamaru, A., Katsukawa, C., Moriya, K., Nakagawa, I., Morisaki, I., et al. 2002. Distribution of emm genotypes and superantigen genes of Streptococcus pyogenes isolated in Japan from 1994 to 1999. Epidemiol. Infect. 128: 397-404.

Murase, T., Suzuki, R., Osawa, R., and Yamai, S. 1999. Characteristics of Streptococcus pyogenes serotype M1 and M3 isolates from patients in Japan from 1981 to 1997. J. Clin. Microbiol. 37: 4131-4134.

Musher, D.M., Hamill, R.J., Wright, C.E., Clarridge, J.E., and Ashton, C.M. 1996. Trends in bacteremic infection due to Streptococcus pyogenes (group A streptococcus), 1986-1995. Emerg. Infect. Dis. 2: $54-56$.

Musser, J.M., Hauser, A.R., Kim, M.H., Schlievert, P.M., Nelson, K., and Selander, R.K. 1991. Streptococcus pyogenes causing toxic-shock-like syndrome and other invasive diseases: Clonal diversity and pyrogenic exotoxin expression. Proc. Natl. Acad. Sci. 88: $2668-2672$

Navarre, W.W. and Schneewind, O. 1999. Surface proteins of gram-positive bacteria and mechanisms of their targeting to the cell wall envelope. Microbiol. Mol. Biol. Rev. 63: 174-229.

Okamoto, S., Kawabata, S., Nakagawa, I., Okuno, Y., Goto, T., Sano, K., and Hamada, S. 2003. Influenza A virus-infected hosts boost an invasive type of Streptococcus pyogenes infection in mice. $J$. Virol. 77: 4104-4112.

Pearson, W.R. 1990. Rapid and sensitive sequence comparison with FASTP and FASTA. Methods Enzymol. 183: 63-98.

Perals, K., Capiaux, H., Vincourt, J.B., Louarn, J.M., Sherratt, D.J., and Cornet, F. 2001. Interplay between recombination, cell division and chromosome structure during chromosome dimer resolution in Escherichia coli. Mol. Microbiol. 39: 904-913.

Podbielski, A., Woischnik, M., Leonard, B.A., and Schmidt, K.H. 1999. Characterization of $n r a$, a global negative regulator gene in group A streptococci. Mol. Microbiol. 31: 1051-1064.
Radding, C.M. 1988. In Genetic recombination (eds. R. Kucherlapati and G.R. Smith) pp.193-229. American Society for Microbiology, Washington, DC

Read, T.D., Brunham, R.C., Shen, C., Gill, S.R., Heidelberg, J.F., White, O., Hickey, E.K., Peterson, J., Utterback, T., Berry, K., et al. 2000. Genome sequences of Chlamydia trachomatis MoPn and Chlamydia pneumoniae AR39. Nucleic Acids Res. 28: 1397-1406.

Sakiyama, T., Takami, H., Ogasawara, N., Kuhara, S., Kozuki, T., Doga, K., Ohyama, A., and Horikoshi, K. 2000. An automated system for genome analysis to support microbial whole-genome shotgun sequencing. Biosci. Biotechnol. Biochem. 64: 670-673.

Segall, A.M. and Roth, J.R. 1994. Approaches to half-tetrad analysis in bacteria: Recombination between repeated, inverse-order chromosomal sequences. Genetics 136: 27-39.

Smoot, J.C., Barbian, K.D., Van Gompel, J.J., Smoot, L.M., Chaussee, M.S., Sylva, G.L., Sturdevant, D.E., Ricklefs, S.M., Porcella, S.F., Parkins, L.D., et al. 2002. Genome sequence and comparative microarray analysis of serotype M18 group A Streptococcus strains associated with acute rheumatic fever outbreaks. Proc. Natl. Acad. Sci. 99: 4668-4673.

Stevens, D.L. 1999. The flesh-eating bacterium: What's next? J. Infect. Dis. 179: 366-374.

Suvorov, A.N. and Ferretti, J.J. 1996. Physical and genetic map of an M type 1 strain of Streptococcus pyogenes. J. Bacteriol. 178: 5546-5549.

Suvorov, A.N. and Ferretti, J.J. 2000. Replication origin of Streptococcus pyogenes, organization and cloning in heterogous systems. FEMS Microbiol. Lett. 185: 293-297.

Tatusov, R.L., Natale, D.A., Garkavtsev, I.V., Tatusova, T.A., Shankavaram, U.T., Rao, B.S., Kiryutin, B., Galperin, M.Y., Fedorova, N.D., and Koonin, E.V. 2001. The COG database: New developments in phylogenetic classification of proteins from complete genomes. Nucleic Acids Res. 29: 22-28.

Tettelin, H., Nelson, K.E., Paulsen, I.T., Eisen, J.A., Read, T.D., Peterson, S., Heidelberg, J., DeBoy, R.T., Haft, D.H., Dodson, R.J., et al. 2001. Complete genome sequence of a virulent isolate of Streptococcus pneumoniae. Science 293: 498-506.

Tettelin, H., Masignani, V., Cieslewicz, M.J., Eisen, J.A., Peterson, S., Wessels, M.R., Paulsen, I.T., Nelson, K.E., Margarit, I., Read, T.D., et al. 2002. Complete genome sequence and comparative genomic analysis of an emerging human pathogen, serotype $\mathrm{V}$ Streptococcus agalactiae. Proc. Natl. Acad. Sci. 99: 12391-12396.

Thompson, J.D., Higgins, D.G., and Gibson, T.J. 1994. CLUSTAL W: Improving the sensitivity of progressive multiple sequence alignment through sequence weighting, position-specific gap penalties and weight matrix choice. Nucleic Acids Res. 22: 4673-4680.

Tillier, E.R. and Collins, R.A. 2000a. The contributions of replication orientation, gene direction, and signal sequences to base-composition asymmetries in bacterial genomes. J. Mol. Evol. 50: $249-257$.

. 2000b. Genome rearrangement by replication-directed translocation. Nat. Genet. 26: 195-197.

Wang, I.N., Smith, D.L., and Young, R. 2000. Holins: The protein clocks of bacteriophage infections. Annu. Rev. Microbiol. 54: 799-825.

Zivanovic, Y., Lopez, P., Philippe, H., and Forterre, P. 1997. Pyrococcus genome comparison evidences chromosomal shuffling-driven evolution. Nucleic Acids Res. 30: 1902-1910.

\section{WEB SITE REFERENCES}

http://www.ncbi.nlm.nih.gov/BLAST/; National Center for Biotechnology Information Web site for BLAST search. http://www.ncbi.nlm.nih.gov/COG/xognitor.html; Phylogenetic classification of proteins

http://www.megasoftware.net/; Phylogenetic tree analysis.

http://sosui.proteome.bio.tuat.ac.jp/sosuiframe0.html; Prediction program of membrane proteins.

http://psort.nibb.ac.jp; Prediction program of protein localizations.

http://genome.gen-info.osaka-u.ac.jp/bacteria/spyo/; S. pyogenes genome project Web site in Genome Information Research Center, Osaka University.

http://www.sanger.ac.uk/Software/Pfam/search.shtml; Sanger Center Web site for the Pfam database.

www.tigr.org; The Institution of Genomic Research Web site.

Received December 13, 2002; accepted in revised form March 25, 2003. 


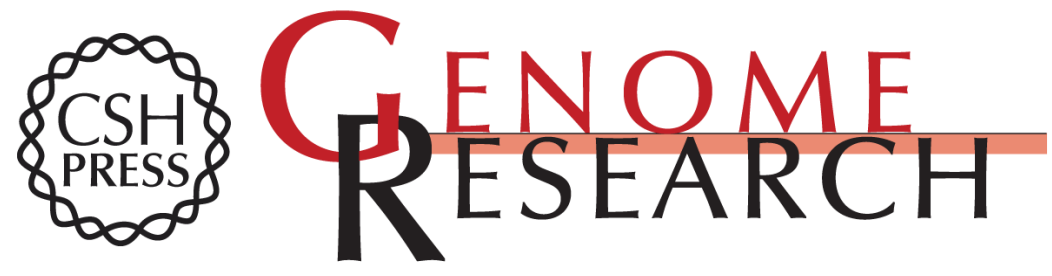

\section{Genome Sequence of an M3 Strain of Streptococcus pyogenes Reveals a Large-Scale Genomic Rearrangement in Invasive Strains and New Insights into Phage Evolution}

Ichiro Nakagawa, Ken Kurokawa, Atsushi Yamashita, et al.

Genome Res. 2003 13: 1042-1055

Access the most recent version at doi:10.1101/gr.1096703

Supplemental
Material http://genome.cshlp.org/content/suppl/2003/06/09/13.6a.1042.DC1

References This article cites 54 articles, 23 of which can be accessed free at:

http://genome.cshlp.org/content/13/6a/1042.full.html\#ref-list-1

License

Email Alerting Receive free email alerts when new articles cite this article - sign up in the box at the Service top right corner of the article or click here.

\section{Affordable, Accurate Sequencing.}

